Dunne, H. P. \& Martin, C. M. Géotechnique [http://dx.doi.org/10.1680/jgeot.16.P.079]

\title{
Capacity of rectangular mudmat foundations on clay under combined loading
}

\author{
H. P. Dunne ${ }^{\mathrm{a}}$, C. M. Martin ${ }^{\mathrm{a}, *}$ \\ ${ }^{a}$ Department of Engineering Science, University of Oxford, UK
}

\begin{abstract}
Rectangular shallow foundations known as mudmats are commonly used in the offshore oil and gas industry. They are often subject to large horizontal forces that can also give rise to overturning and torsional moments. This paper focuses on analysing the ultimate capacity of a rigid rectangular mudmat resting on the surface of, or embedded in, homogeneous undrained clay. Realistic three-dimensional load combinations are applied, based on the combined horizontal, moment and torsional loading generated by a horizontal force applied within the envelope of the mudmat and the equipment that it supports. Analytical lower- and upper-bound plasticity calculations are performed for a surface footing under combined horizontal and torsional loading, while embedded footings and more complex loading arrangements are considered using three-dimensional finite element limit analysis. The undrained soil is modelled as a rigid-plastic von Mises material, and the interface between the external sides of the mudmat and the soil is modelled with both unlimited and zero tension capacity. Design charts are presented and relationships between loading combinations and failure mechanisms are explored.
\end{abstract}

Keywords: bearing capacity; clays; footings/foundations; numerical modelling; limit state design/analysis

\section{Introduction}

Shallow foundations known as mudmats are frequently used to support subsea infrastructure such as pipeline end terminations and pipeline end manifolds. These are connected to pipelines through jumpers, which can be situated at a height above the mudmat, and are often not aligned along the plan view axes of the mudmat. The jumper experiences horizontal expansion and contraction forces from the pipeline as it undergoes temperature changes during operation. Depending on the jumper arrangement, this can induce biaxial horizontal loads in conjunction with biaxial overturning moments and torsional loading on the mudmat. It is well known that failure of mudmats can be significantly influenced by torsional loading (Finnie \& Morgan, 2004; Murff et al., 2010; McDonald et al., 2014; Martin et al., 2015). This has been further highlighted by the development of additions to shallow mudmat foundations, such as corner piles, to help improve torsional capacity (Dimmock et

*corresponding author

helen.dunne@eng.ox.ac.uk (H. P. Dunne), chris.martin@eng.ox.ac.uk (C. M. Martin) 
al., 2013). Vertical loading on a mudmat is predominantly due to the self-weight of the supported infrastructure, but this load is typically small compared with the ultimate vertical bearing capacity of the mudmat.

Classical bearing capacity theory, stemming from the methods of Brinch Hansen (1970) and Vesic (1975), is adopted in the DNV (1992) and ISO (2003) design guidelines for offshore shallow foundations. This approach has been found to be inaccurate for foundations where the primary loading is not vertical, and for foundations on undrained clay where detachment under short-term moment loading is prevented through under-base skirts (Martin, 1994; Ukritchon et al., 1998; Bransby \& Randolph, 1998). An increasingly common design approach, particularly where significant torsional loading is present, is the use of three-dimensional (3D) finite element analysis (FEA) (Yun et al., 2009; Nouri et al., 2014; Feng et al., 2014). This improves accuracy, but can be time-consuming as a mesh refinement study is required to verify the quality of the numerical solution.

As offshore oil and gas developments continue to move into deeper water, pipelines are subjected to increasing levels of temperature and pressure change, leading to larger loads for mudmats to resist. However, in practice mudmat dimensions are restricted by the size of their installation vessels, increasing the importance of accurate bearing capacity analysis. Compared with conventional 3D FEA, carrying out both lower bound (LB) and upper bound (UB) finite element limit analysis (FELA) is advantageous, as the accuracy of the numerical solution is directly quantifiable.

In this paper, analytical plasticity calculations and 3D FELA are used to study the ultimate capacity of both surface and embedded mudmats subject to combined loading on homogeneous undrained clay. The notation and sign conventions adopted here are shown in Fig. 1. The paper begins by considering combined horizontal and torsional loading $\left(F_{x}\right.$, $\left.F_{y}, M_{z}\right)$. As it is considered improbable that a mudmat would be loaded from outside its plan area, emphasis is given to horizontal loads applied at points within the plan area of the mudmat, generating what are referred to here as 'feasible' levels of torsion. Next, the paper considers horizontal forces applied at an eccentricity from, and a height above, the load reference point ( $\mathrm{O}$ in Fig. 1). This results in five degree-of-freedom loading $\left(F_{x}, F_{y}\right.$, $\left.M_{x}, M_{y}, M_{z}\right)$. Finally, the capacity of surface and embedded mudmats under pure vertical loading is closely bracketed using 3D FELA. A prescribed fraction of the ultimate vertical capacity is then applied to the mudmat as a vertical dead load, and horizontal forces are again applied at a range of eccentricities from, and heights above, the load reference point.

The overall objective of the paper is to explore the interaction between the various loading components in a comprehensive manner, and to examine the corresponding mudmat failure mechanisms. Ultimate horizontal capacities (normalised by undrained shear strength and footing area) are presented in the form of design charts showing the influence of loading eccentricity and height. The effect of varying the tensile capacity of the interface between the soil and the sides of the mudmat, for various soil weights, is also considered.

\section{Background}

All of the literature reviewed in this section relates to shallow foundations on undrained clay soil idealised as an elastic-plastic or rigid-plastic material.

Murff \& Miller (1977) used UB limit analysis to study the bearing capacity of offshore structures and found that torsion significantly reduced the sliding resistance of their example. Finnie \& Morgan (2004) studied the effect of torsional loads on subsea structures 
including shallow foundations. It was demonstrated that the governing load case for a shallow foundation can be the torsional effect of a horizontal load applied at an eccentricity from the foundation centre. A limit equilibrium method was used to determine the factor of safety against torsional sliding for a square surface footing. This analysis was expanded upon by Yun et al. (2009), where it was supplemented by 3D FEA. Failure envelopes for circular, square and rectangular surface footings subject to combined vertical, horizontal and torsional loading were presented. It was found that FEA overestimated the torsional capacity of a square footing by $11 \%$ when compared with the analytical solution.

Murff et al. (2010) applied UB limit analysis to shallowly embedded square and rectangular footings subject to combined horizontal and torsional loading. The footing was modelled as a rigid body, displacing wedges of soil along planes at $45^{\circ}$ from the base of the foundation to the soil surface. The failure mechanism that was studied involved an active wedge of soil being pulled behind the footing and a passive wedge of soil being pushed in front.

Results from 3D FEA undertaken by Nouri et al. (2014) were found to match the UB equations derived by Murff et al. (2010) reasonably well. The FEA was limited to horizontal loads applied parallel to the plan view axes. It was found that although the size of the horizontal-torsional failure envelope increased with embedment depth, its shape remained similar.

Feng et al. (2014) used 3D FEA to study six degree-of-freedom loading on shallowly embedded mudmats. The focus of this study was on simplifying the failure envelopes for various loading combinations into curve fits for easy implementation in a spreadsheet, or other software, for use in preliminary design. A realistic design case study of a mudmat subject to six degree-of-freedom loading was presented.

Martin et al. (2015) applied 3D FELA to a rectangular surface footing subject to six degree-of-freedom loading. Both LB and UB analyses were performed for the individual load components, and for biaxial moment loading. An adapted version of the case study from Feng et al. (2014) was also analysed using 3D FELA, and the failure mechanism was identified as interface sliding/twisting. It was found that the collapse load multiplier was not affected by doubling or removing the overturning moments, but it was significantly altered when the torsional moment was doubled or removed.

Generally speaking, previous research focusing on mudmat capacity under combined hor-

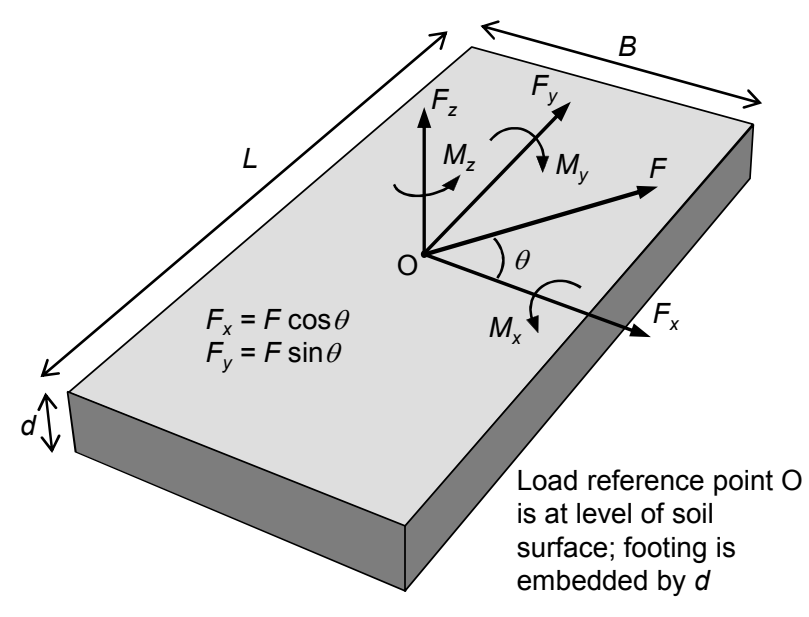

Figure 1: Notation and sign conventions 
izontal and torsional loading has not considered the additional effect of biaxial overturning moments. Research on combined six degree-of-freedom loading has not been performed with a focus on practically relevant levels of torsion and overturning moment, and there has been little interpretation of failure mechanisms. This paper seeks to address these issues systematically, and to provide new mechanistic insights. Both surface and embedded foundations are considered, but for simplicity attention is confined to homogeneous undrained soil (no strength increase with depth).

\section{Problem definition}

As shown in Fig. 1, the skirted mudmat is modelled as an embedded rigid body of breadth $B$ along the $x$-axis, length $L$ along the $y$-axis, and depth $d$ along the $z$-axis. The length-to-breadth aspect ratio is fixed at $L / B=2$, as this is a typical value adopted in practice (Feng et al., 2014). In treating the embedded mudmat as a rigid body, it is tacitly assumed that sufficient interior skirts are present to fully confine the soil plug (Mana et al., 2013). The base of the rigid body is modelled as fully rough, with unlimited interface tension capacity (cf. Bransby \& Randolph, 1998). The soil is idealised as a homogeneous, rigid-plastic material with undrained shear strength $s_{\mathrm{u}}$ and submerged unit weight $\gamma^{\prime}$. Along the mudmat sides, both unlimited-tension and zero-tension interfaces with the adjacent soil are considered. In practice, particularly in soft clays close to the seabed, a zero-tension interface would be the recommended case for a conservative assessment of capacity.

Previous research has shown that the inclusion of soil weight in the model does not affect the calculated capacity of an embedded mudmat if an unlimited-tension interface is assumed along the sides, though it can when a zero-tension interface is assumed. If a zero-tension interface is assumed and the soil is modelled as weightless, a gap forms behind the mudmat if it displaces horizontally. Consequently, there is no active soil mobilisation. If a zero-tension interface is assumed and soil weight is included in the model, soil may remain attached on the active side, depending on the dimensionless weight-to-strength ratio $\gamma^{\prime} B s_{\mathrm{u}}$, leading to enhanced capacity. It is shown in this paper that if a mudmat is modelled in weightless soil with unlimited-tension and zero-tension interfaces along the sides, the resulting capacities will bracket the corresponding capacity of a mudmat in soil with weight, irrespective of the assumed interface tension on the sides.

The forces $\left(F_{x}, F_{y}, F_{z}\right)$ and moments $\left(M_{x}, M_{y}, M_{z}\right)$ denote loads applied to the soil by the footing. The load reference point is taken at the axis origin, which lies in the plan centre of the mudmat at the level of the soil surface (see Fig. 1). Complexity is added to the analysis in three stages.

\subsection{Stage 1: Horizontal and torsional loading}

When considering combined $\left(F_{x}, F_{y}, M_{z}\right)$ loading, emphasis is given to horizontal loads generating 'feasible' levels of torsion, as discussed in the Introduction and clarified in Figs $2(\mathrm{a})-2(\mathrm{c})$. The largest feasible eccentricity $e_{\max }$ occurs when a force is applied at the mudmat corner at an angle $\theta=\tan ^{-1}(B / L)$, which is $26.6^{\circ}$ due to the $2: 1$ aspect ratio considered in this paper.

\subsection{Stage 2: Horizontal, torsional and moment loading}

Horizontal forces are applied at a height $h$ above the mudmat, resulting in combined horizontal and moment loading (Figs 2(d)-2(f)). Forces applied at both an eccentricity $e$, and a height $h$, with respect to the mudmat centre result in five degree-of-freedom loading $\left(F_{x}, F_{y}, M_{x}, M_{y}, M_{z}\right)$. 


\subsection{Stage 3: Horizontal, torsional, moment and vertical loading}

The ultimate vertical bearing capacity $\left(F_{z 0}\right)$ is calculated using a refined FELA mesh to closely bracket the solution. A vertical dead load equal to $0.5 F_{z 0}$ is then applied while the mudmat is again subjected to five degree-of-freedom live loading $\left(F_{x}, F_{y}, M_{x}, M_{y}, M_{z}\right)$ as outlined in Stage 2.

\section{Finite element limit analysis}

All analyses were performed using OxLim, a FELA program developed by the second author. OxLim has been used extensively for the analysis of plane strain problems (e.g. Martin, 2011; Martin \& White, 2012; Mana et al., 2013; Dunne et al., 2015), and more recently for 3D problems (Martin et al., 2015).

When using OxLim to solve a 3D problem, the soil domain is first discretised into a mesh of tetrahedral elements, and relevant boundary conditions are specified. The program then sets up two separate constrained optimisation problems that together allow rigorous bracketing of the exact collapse load multiplier (i.e. the factor by which the specified live loads must be increased to cause plastic failure). For this study, the LB analyses used a piecewise linear stress field, and the UB analyses used a piecewise linear velocity field. The average of the bounds, $(L B+U B) / 2$, is used as the best estimate solution, and the

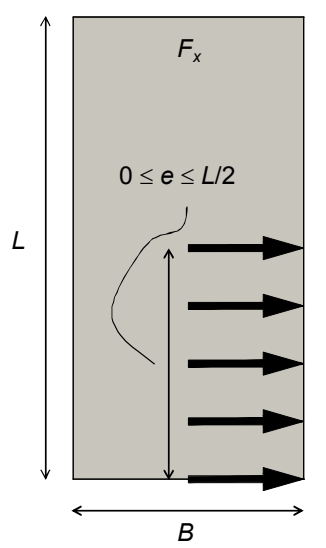

(a)

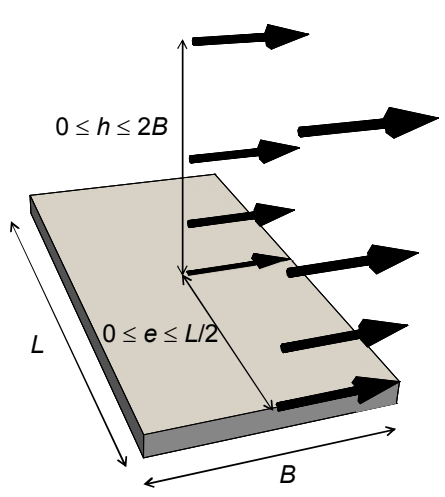

(d)

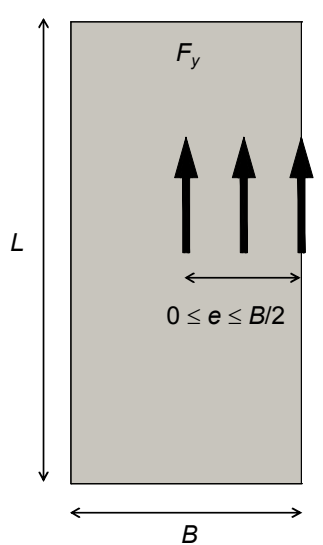

(b)

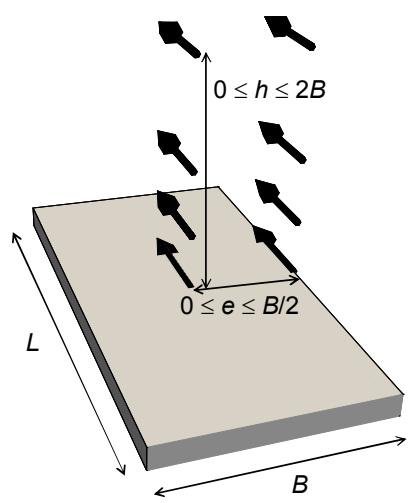

(e)

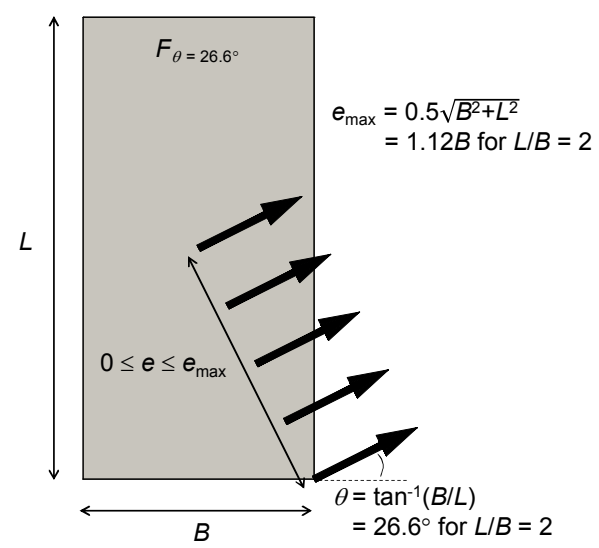

(c)

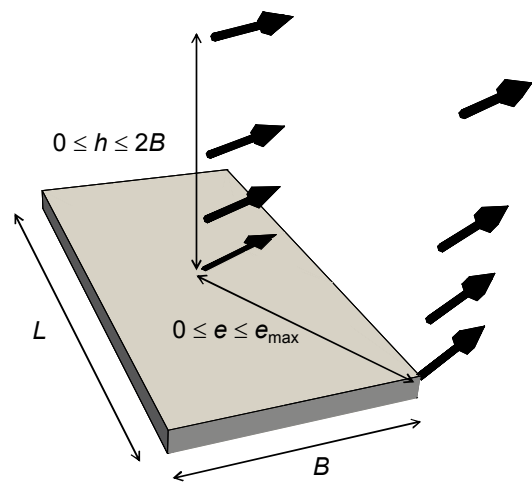

(f)

Figure 2: Footing loading arrangement: (a)-(c) feasible eccentricity $e$ of horizontal loading; (d)-(f) horizontal loading applied at height $h$ 


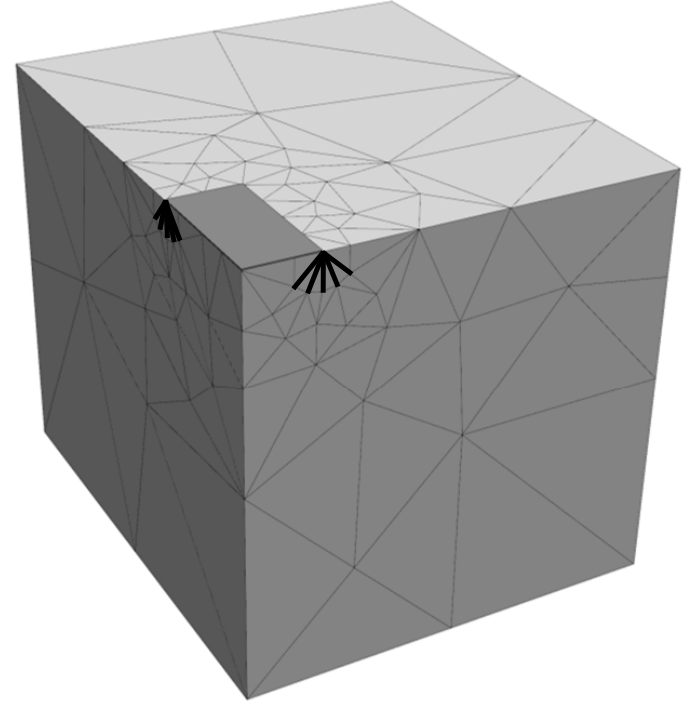

(a)

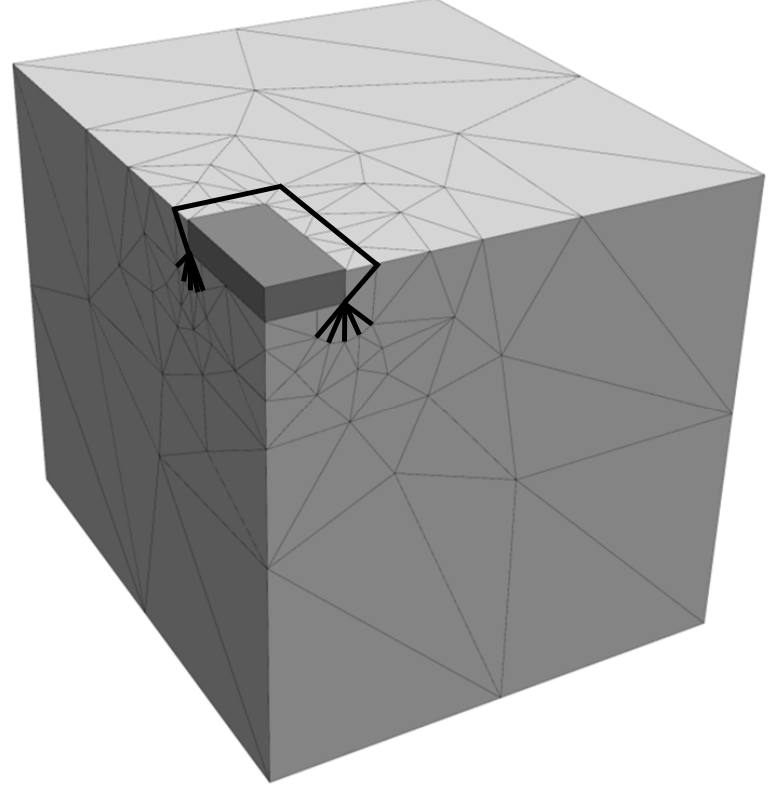

(b)

Figure 3: Initial FELA mesh of quarter model showing prescribed facets in the mesh as bold lines: (a) surface footing; (b) embedded footing

associated bracketing error is calculated as $\pm(U B-L B) /(U B+L B)$. The results presented for this study have a maximum bracketing error of $\pm 6 \%$.

In the OxLim analyses the undrained soil was modelled as a rigid-plastic material obeying the von Mises failure criterion. This allowed both the LB and UB analyses to be cast as standard second-order cone programming problems and solved using specialised software (Makrodimopoulos \& Martin, 2006; 2007; MOSEK ApS, 2014). Use of the Tresca criterion would have resulted in semidefinite programming problems (Martin \& Makrodimopoulos, 2008), which are more challenging to solve. The von Mises yield strength in pure shear, $k$, was equated with the Tresca shear strength, $s_{\mathrm{u}}$, such that the two criteria were matched for deformation in plane strain (and for shearing of an interface layer). In the analysis of 3D shallow foundation problems this has been found to provide better agreement between the predicted bearing capacities, compared with matching the strengths of the two criteria under triaxial conditions (Gourvenec et al., 2006). The value of $k$ was assumed as homogeneous throughout the soil domain.

OxLim uses adaptive mesh refinement (if required) to improve the bracketing of the exact collapse load multiplier. An adaptivity strategy based on the spatial variation of the maximum shear strain rate in the UB velocity field has been used in several previous studies of plane strain problems (e.g. Martin, 2011; Martin \& White, 2012; Mana et al., 2013). A similar technique for 3D FELA can readily be implemented with the help of a suitable mesh generator. For this study all mesh generation was performed using the open-source code TetGen (Si, 2013).

The soil domain was sized such that it comfortably contained the foundation failure mechanism for all of the load combinations considered. For a surface footing, a soil domain $7 B \times 7 B$ in plan and $3.5 B$ deep was sufficient, with larger domains used for the embedded footings. As shown in Fig. 3, sheaves of 'singularity facets' were attached to the edges of the footing base, and for embedded footings, additional facets rising at $45^{\circ}$ from the footing 


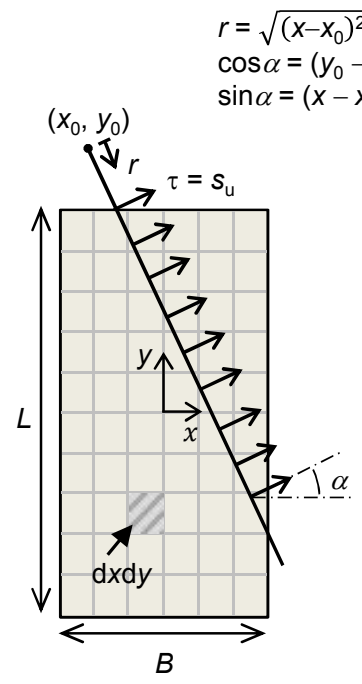

(a)

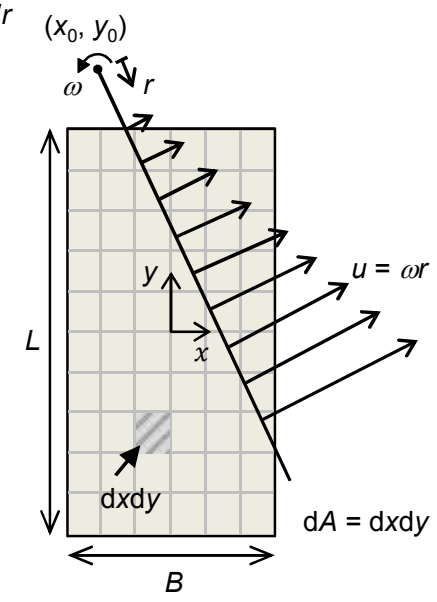

(b)

Figure 4: Analytical solution for combined horizontal and torsional loading of a surface footing: (a) lower bound shear stresses; (b) upper bound velocities

base to the soil surface were included. When these facets are constrained to be present in an otherwise unstructured mesh, the FELA bounds converge much more rapidly when compared with using a completely unstructured mesh.

As already noted, the interface at the base of the embedded rigid foundation was modelled as fully rough, with unlimited tensile capacity. The mudmat sides were conservatively modelled as fully smooth, and the interface was modelled with either unlimited tensile capacity, $T=\infty$, or zero tensile capacity, $T=0$.

\section{Results}

\subsection{Surface footing - horizontal and torsional loading}

A surface footing subject to combined horizontal and torsional loading was analysed directly by applying the LB and UB plasticity theorems to the interface, and numerically by using 3D FELA.

Analytical LB values for $F_{x}, F_{y}$ and $M_{z}$ were found by numerically integrating the shear stress components $\tau_{x}$ and $\tau_{y}$ that would be induced by footing rotation about a prescribed point $\left(x_{0}, y_{0}\right)$, as shown in Fig. $4(\mathrm{a})$ :

$$
\begin{gathered}
F_{x}=\int_{-L / 2}^{+L / 2} \int_{-B / 2}^{+B / 2} \tau_{x} \mathrm{~d} x \mathrm{~d} y \\
F_{y}=\int_{-L / 2}^{+L / 2} \int_{-B / 2}^{+B / 2} \tau_{y} \mathrm{~d} x \mathrm{~d} y \\
M_{z}=\int_{-L / 2}^{+L / 2} \int_{-B / 2}^{+B / 2}\left(x \tau_{y}-y \tau_{x}\right) \mathrm{d} x \mathrm{~d} y
\end{gathered}
$$

where $\tau_{x}=s_{\mathrm{u}} \cos \alpha$ and $\tau_{y}=s_{\mathrm{u}} \sin \alpha$, with $\cos \alpha$ and $\sin \alpha$ calculated as shown in Fig. 4 . It is acknowledged that this lower bound solution is not fully rigorous as it does not extend the interface stress field into the remainder of the semi-infinite soil domain. However, this 
is considered a formality in light of the essentially identical numerical LB solution obtained using 3D FELA (see below).

The analytical UB solution was formulated by equating the internal and external work rates when the footing rotates with a virtual angular velocity $\omega$ about $\left(x_{0}, y_{0}\right)$, as shown in Fig. 4(b):

$$
\begin{gathered}
\dot{W}_{\mathrm{int}}=s_{\mathrm{u}} \omega \int_{-L / 2}^{+L / 2} \int_{-B / 2}^{+B / 2} r \mathrm{~d} x \mathrm{~d} y \\
\dot{W}_{\mathrm{ext}}=F_{x} \omega y_{0}-F_{y} \omega x_{0}+M_{z} \omega
\end{gathered}
$$

with $r$ calculated as shown in Fig. 4. The 3D failure surface obtained by solving these equations numerically for a range of rotation centres is shown in Fig. 5(a). It should be noted that the complete failure surface is symmetrical about the $F_{x}-F_{y}, F_{x}-M_{z}$, and $F_{y}-M_{z}$ planes. The LB equations produced results which matched precisely with the UB equations, indicating an exact theoretical solution. The circular contour when $M_{z}=0$ confirms that the horizontal capacity of the footing in this case is always equal to the interface shear capacity, $B L s_{\mathrm{u}}$, irrespective of the relative magnitudes of $F_{x}$ and $F_{y}$.

Figure 5(b) shows that excellent agreement was found between the analytical solution and the results obtained using 3D FELA. The FELA results for horizontal loading with $M_{z}=0$ solved to $\pm 0.01 \%$ bracketing error without any mesh refinement, while in pure torsion $\left(F_{x}=F_{y}=0\right)$ an unrefined mesh solved to $\pm 2 \%$. Each analysis completed in less than $10 \mathrm{~s}$, with the failure mechanism always involving pure interface shearing between the footing and the soil. As the loading direction $\theta$ (Fig. 1) is varied, the feasible torsion limit

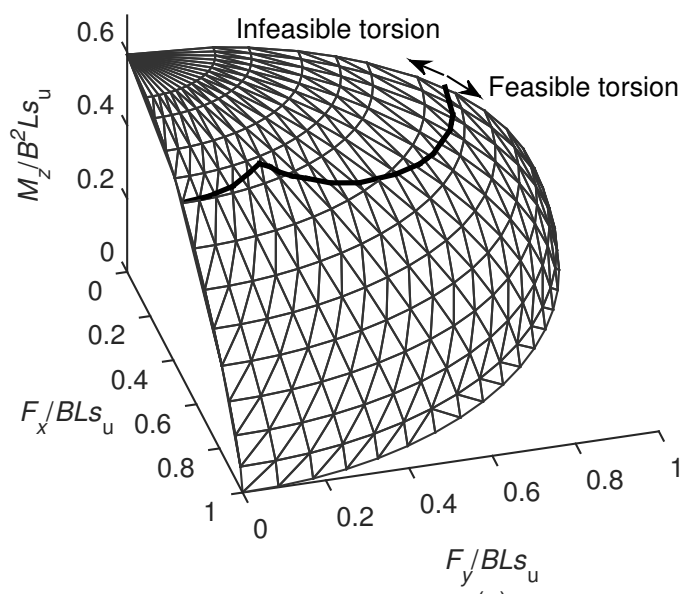

(a)
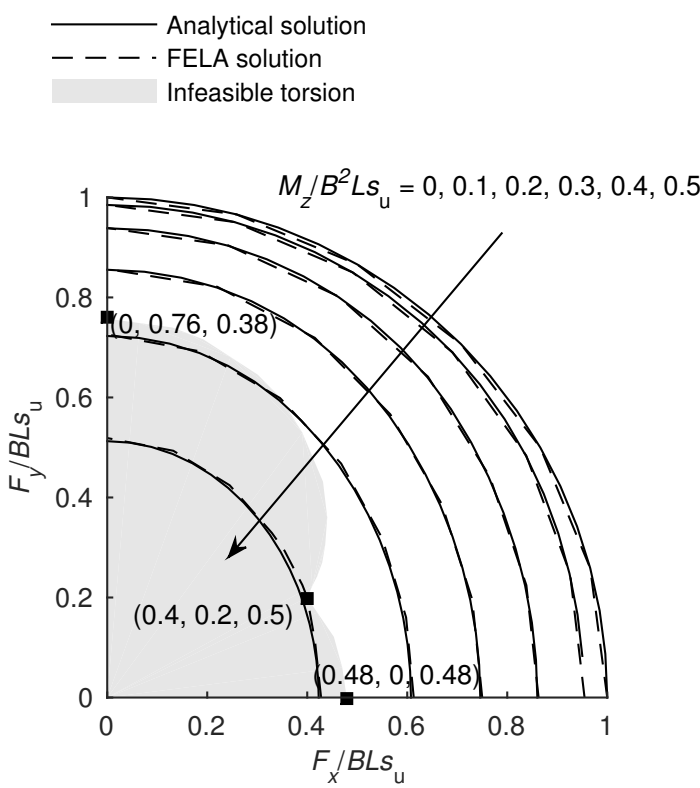

(b)

Figure 5: Failure envelope for a surface footing subject to combined horizontal and torsional loading, showing region of feasible torsion: (a) analytical solution; (b) contour plot comparing analytical solution with FELA solution 


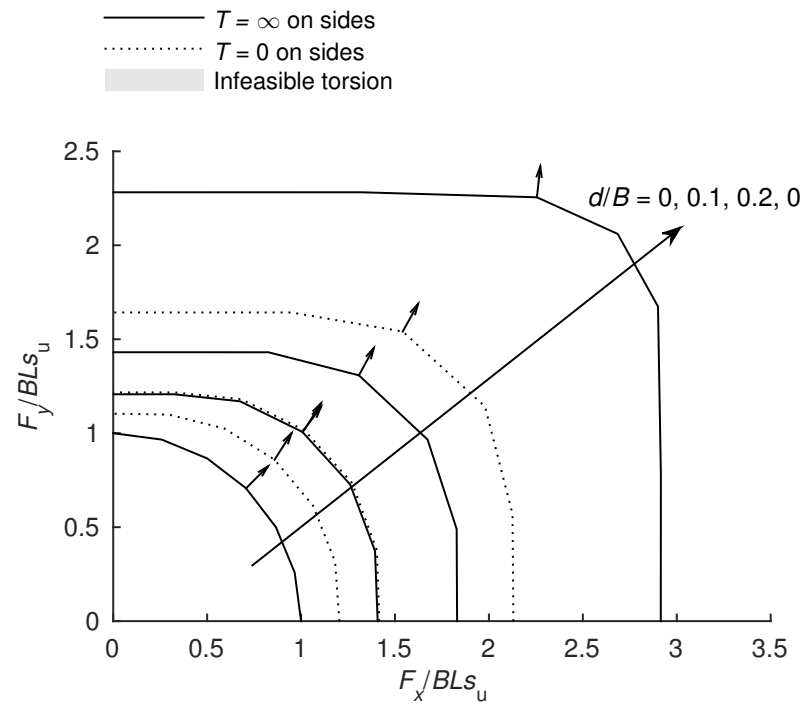

(a)

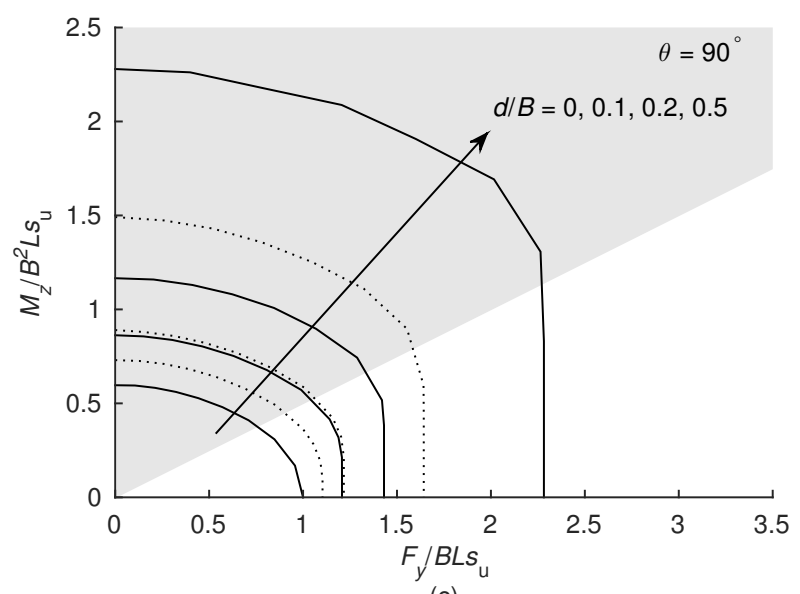

(c)

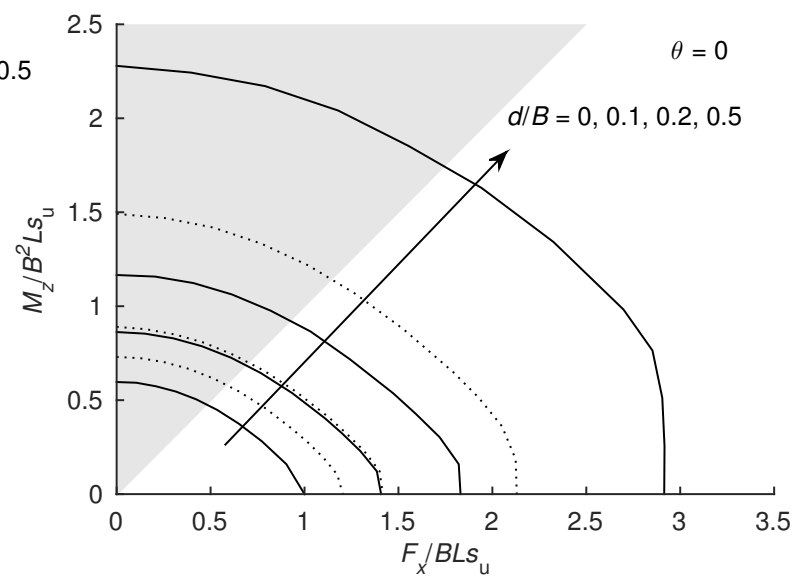

(b)

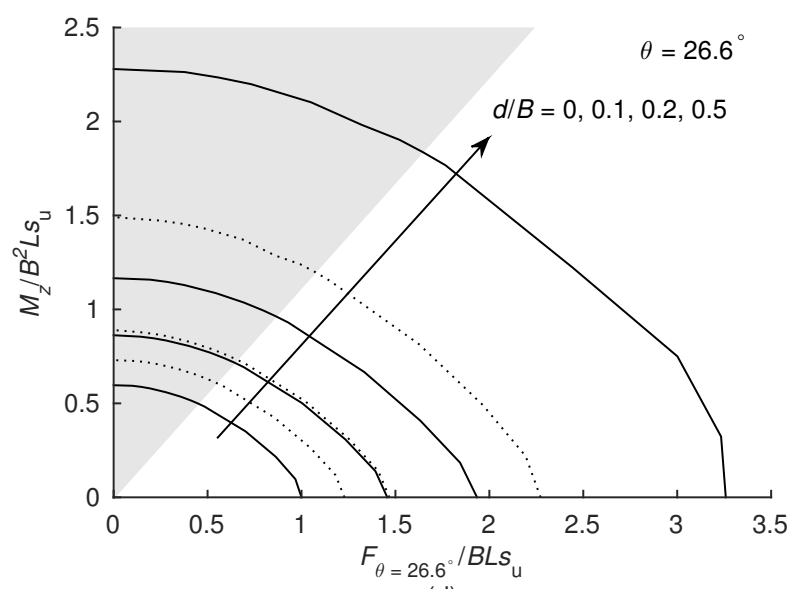

(d)

Figure 6: Failure envelopes for surface and embedded footings subject to combined horizontal and torsional loading: (a) $F_{x}-F_{y}\left(M_{z}=0\right)$; (b) $F_{x}-M_{z}$; (c) $F_{y}-M_{z} ;$ (d) $F_{\theta=26.6}-M_{z}$

shown in Fig. 5(b) increases from $M_{z}=0.48 B^{2} L s_{\mathrm{u}}$ when $\theta=0\left(F_{y}=0\right)$, to a maximum of $M_{z}=0.5 B^{2} L s_{\mathrm{u}}$ when $\theta=26.6^{\circ}$, before reducing to $M_{z}=0.38 B^{2} L s_{\mathrm{u}}$ when $\theta=90^{\circ}\left(F_{x}=0\right)$.

\subsection{Embedded footing - horizontal and torsional loading}

Embedded footings subject to combined horizontal and torsional loading mobilise wedges of soil adjacent to the mudmat at failure, significantly increasing their capacity when compared with surface footings. Because of the 2:1 aspect ratio considered in this paper, embedded footings have a larger capacity under pure $F_{x}$ loading than under pure $F_{y}$ loading. This is shown in Fig. 6(a), where the failure envelopes for combined $F_{x}-F_{y}$ loading are no longer circular when the footing is embedded. Failure envelopes for surface and embedded footings subject to three cases of combined horizontal loading $\left(F_{x}, F_{y}, F_{\theta=26.6^{\circ}}\right)$ and torsional loading are shown in Figs 6(b)-6(d), with zones of infeasible torsion shaded.

Comparing the solid and dotted lines in Fig. 6, it can be seen that enforcement of a tension cutoff on the sides of the mudmat reduces the resistance to combined horizontal 
and torsional loading, but the shape of the failure envelope does not change appreciably. The failure mechanism for an embedded footing with $T=\infty$ on the sides, subject to $F_{y}$ loading, is shown in Fig. 7(a). Wedges of soil are displaced on either side of the footing in the direction of the horizontal load. Figure 7(b) shows the corresponding failure mechanism when $T=0$ on the sides. In this case, a wedge of soil is only displaced in front of the footing and a gap forms behind. The footing in Fig. 7(a) mobilises more soil at failure than the footing in Fig. 7(b), resulting in a higher capacity.

Plastic displacement vectors, inclined at angle $\zeta$ to the $F_{x}$ axis, are plotted in Fig. 6(a) for a footing subject to horizontal loading in the direction $\theta=45^{\circ}$ (equal components of $F_{x}$ and $\left.F_{y}\right)$. As expected, a surface footing $(d / B=0)$ has a plastic displacement direction $\zeta=\theta$, and the failure mechanism shows the footing translating in the direction of the load (Fig. 8(a)). As the embedment ratio increases, however, the footing translates more in the $y$-direction than the $x$-direction, even though the direction of loading remains the same. A footing embedded with $d / B=0.5$ has a displacement vector at $\zeta=84^{\circ}$ when subject to loading at $\theta=45^{\circ}$. This corresponds to translation that is predominantly in the $y$-direction, as is clear from the failure mechanism (Fig. 8(c)). The failure envelope for a footing embedded with $d / B=0.5$ and $T=\infty$ on the sides comprises essentially linear sections parallel to the axes when $F_{x}<2.3 B L s_{\mathrm{u}}$ and also when $F_{y}<1.7 B L s_{\mathrm{u}}$ (Fig. 6(a)). In general, the failure mechanism for a footing under combined $F_{x}-F_{y}$ loading changes from oblique translation at lower embedments towards axis-aligned translation as footing embedment increases.

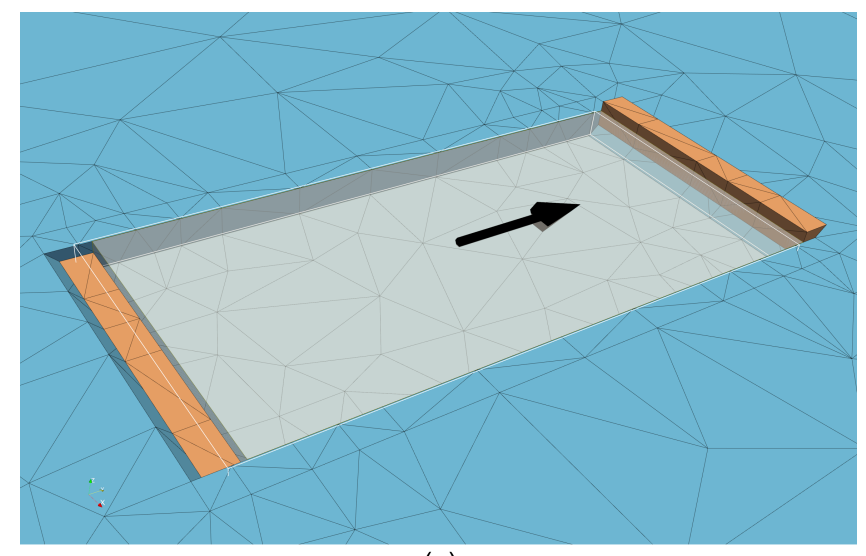

(a)

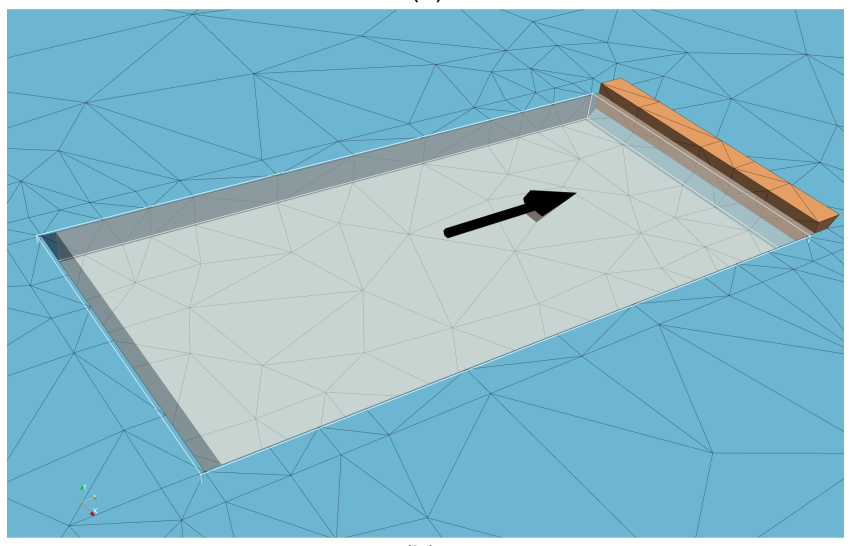

(b)

Figure 7: Failure mechanisms for an embedded footing $(d / B=0.1)$, subject to horizontal loading $F_{y}$, showing effect of interface tension capacity on sides: (a) $T=\infty$; (b) $T=0$. Shaded by UB velocity magnitude 


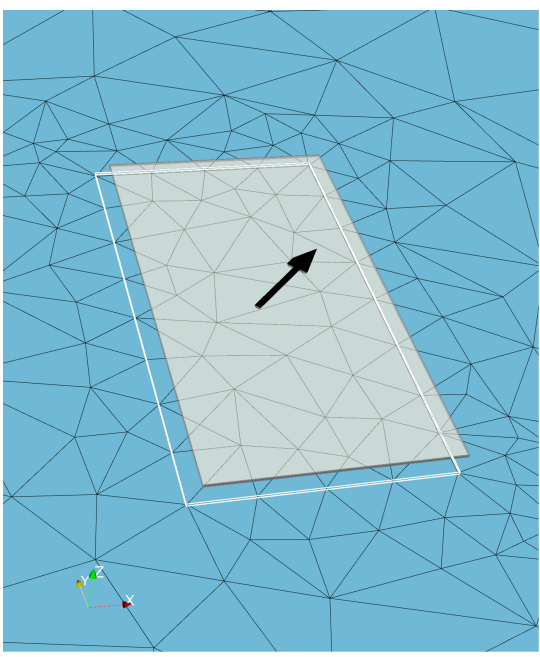

(a)

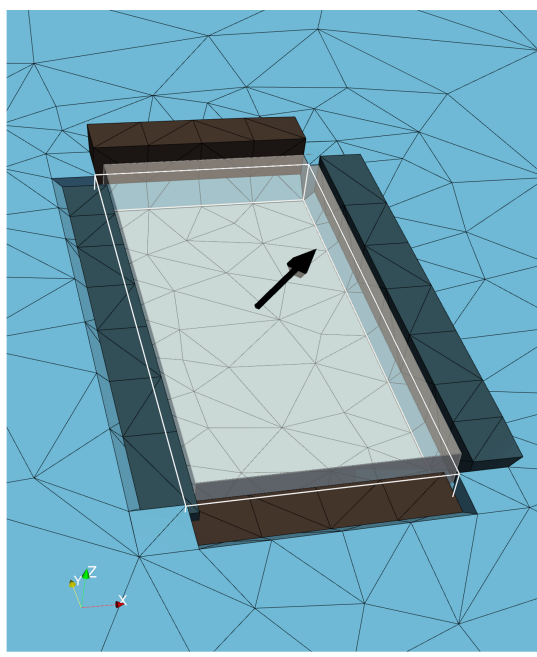

(b)

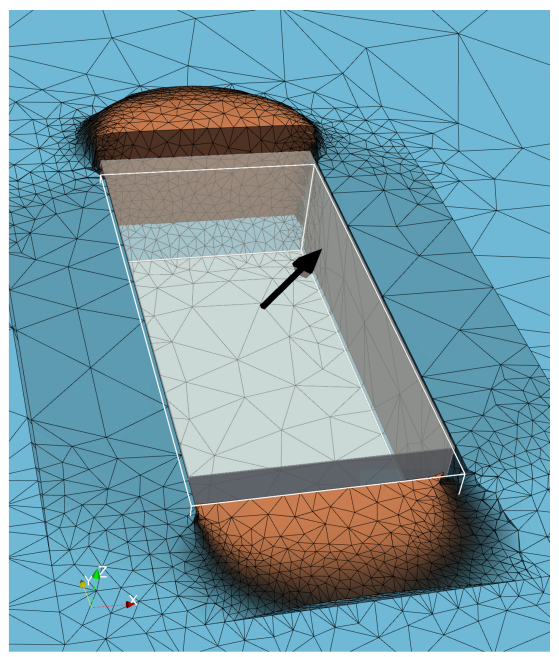

(c)

Figure 8: Failure mechanisms for footings subject to horizontal loading $F_{\theta=45^{\circ}}$, showing effect of embedment: (a) $d / B=0 ;$ (b) $d / B=0.2$; (c) $d / B=0.5$. $T=\infty$ on sides. Shaded by UB velocity magnitude

Figure 9 shows capacity charts for an embedded footing with $d / B=0.2$ subject to horizontal forces applied at a range of eccentricities from the footing centre. The capacity of a footing embedded in weightless soil is considerably larger with $T=\infty$ along the sides than with $T=0$ along the sides. When soil weight $\gamma^{\prime}$ is included in the analysis, the capacity with $T=\infty$ remains unchanged, but the capacity with $T=0$ increases. The capacity when $T=0$ increases with increasing normalised soil weight $\gamma^{\prime} B s_{\mathrm{u}}$, but it never exceeds the capacity when $T=\infty$.

This can be explained by considering the corresponding failure mechanisms. In weightless soil, when $T=0$ a gap forms behind a footing subject to horizontal loading (as in Fig. 7(b)), while when $T=\infty$ a gap cannot form (as in Fig. 7(a)) and an active region of soil is mobilised behind the footing. When soil weight is included in the analysis, the failure mechanism when $T=\infty$ is unchanged, while when $T=0$ soil may mobilise behind the footing, suppressing the formation of a gap. Whether soil mobilises behind the footing is dependent on the normalised soil weight $\gamma^{\prime} B s_{\mathrm{u}}$, with heavier soil more inclined to mobilise. As more soil cannot be mobilised than when $T=\infty$, this provides an upper limit for the capacity of a footing in soil with weight. Less soil cannot be mobilised than when $T=0$ in weightless soil, and as such this provides a lower limit for the capacity of a footing in soil with weight. For this reason, in all subsequent analyses the soil is modelled as weightless, with either $T=\infty$ or $T=0$ on the mudmat sides.

Failure mechanisms for an embedded footing with $d / B=0.2$, loaded both concentrically and at the maximum feasible eccentricity, are shown in Fig. 10. Comparing Figs 10(a) and 10(c), a footing subject to $F_{x}$ loading mobilises larger wedges of soil than a footing subject to $F_{y}$ loading, resulting in greater capacity (compare Figs $9(\mathrm{a})$ and $9(\mathrm{~b})$ ). A footing subject to $F_{x}$ at the maximum feasible eccentricity has significant twisting visible in the failure mechanism, and the capacity reduces by nearly 50\% (Figs 10(b) and 9(a)). For a footing subject to $F_{y}$, the maximum feasible eccentricity is smaller, and torsion causes only a $12 \%$ reduction in capacity (Figs $10(\mathrm{~d})$ and $9(\mathrm{~b})$ ). The largest reduction in capacity due to eccentric horizontal loading occurs for a footing subject to $F_{\theta=26.6^{\circ}}$, with significant twisting visible in the failure mechanism and a $55 \%$ reduction in capacity (Figs 10(f) and 9(c)). 

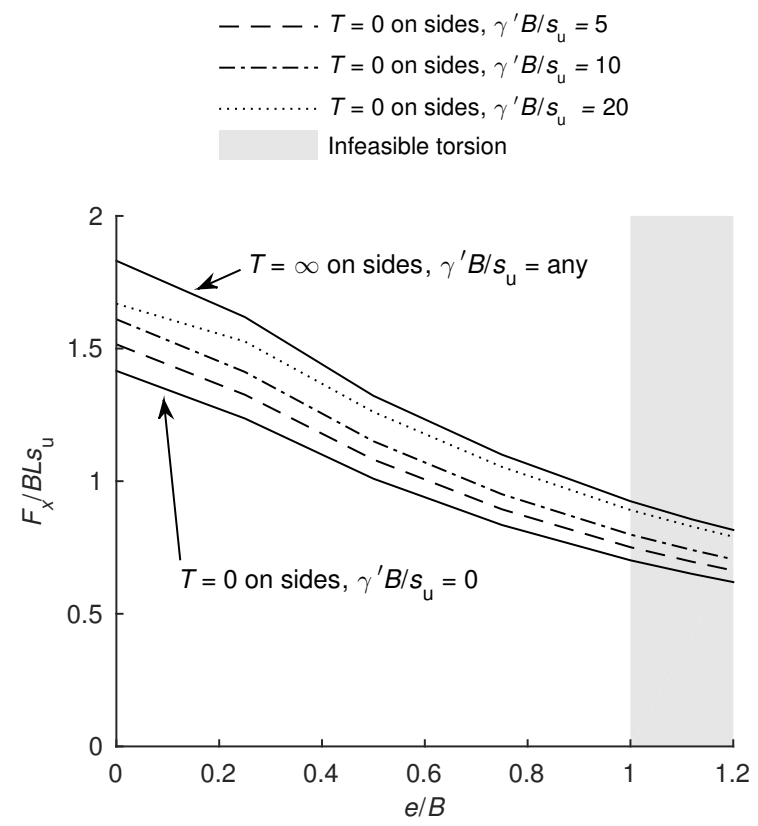

(a)

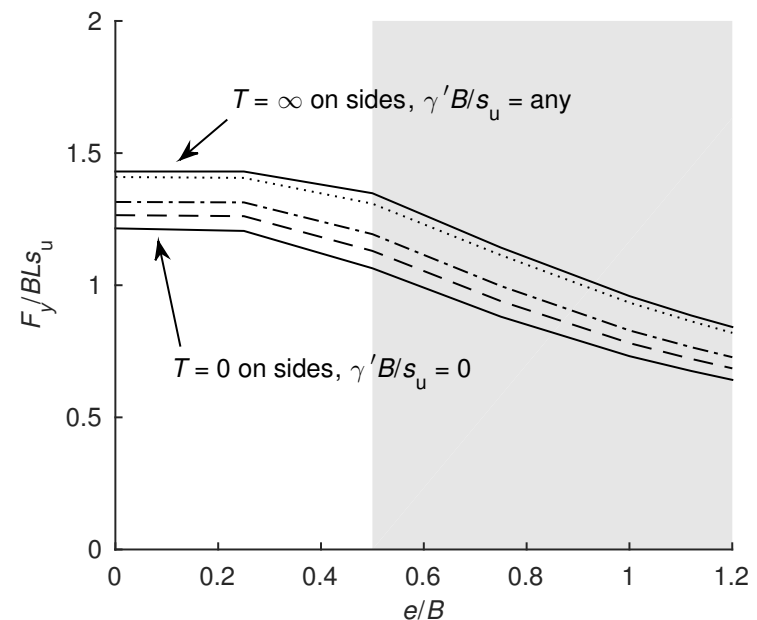

(b)

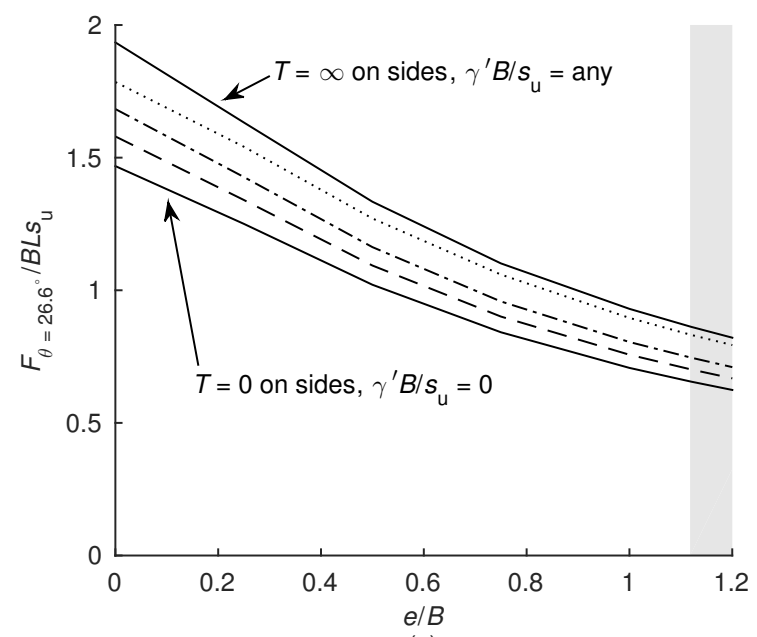

(c)

Figure 9: Capacity of an embedded footing $(d / B=0.2)$ subject to horizontal loading at a range of eccentricities, showing effect of normalised soil weight $\gamma^{\prime} B / s_{\mathrm{u}}$ : (a) $F_{x}$; (b) $F_{y}$; (c) $F_{\theta=26.6^{\circ}}$ 


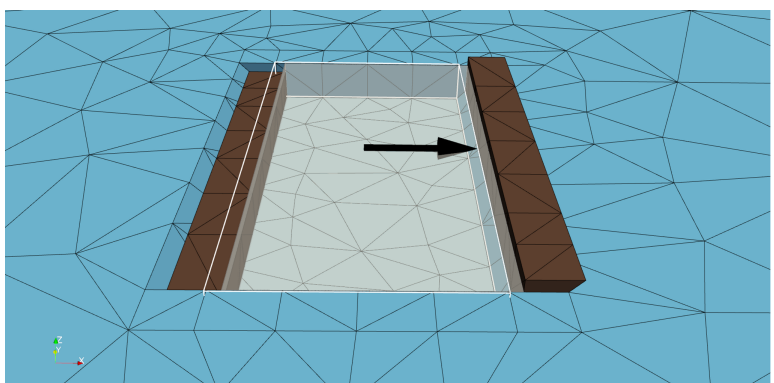

(a)

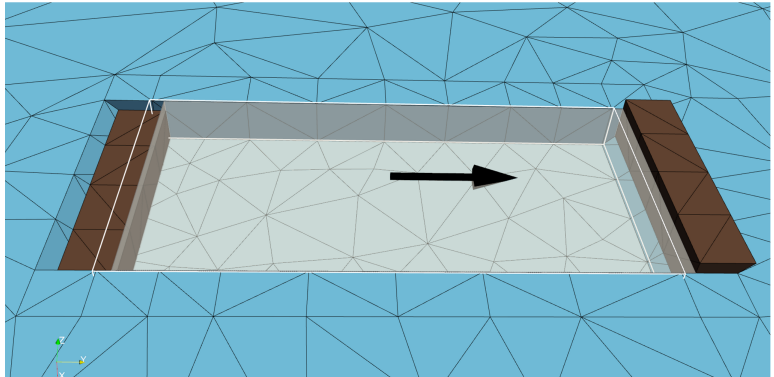

(c)

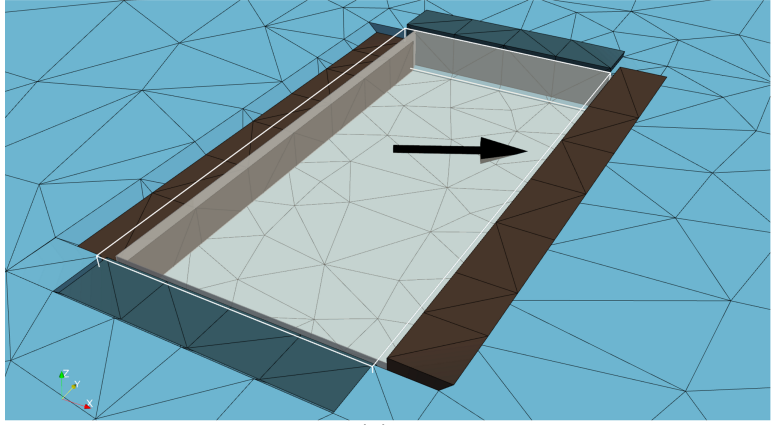

(e)

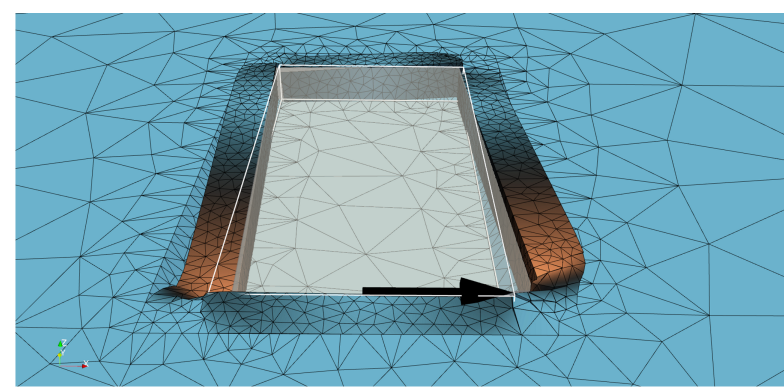

(b)

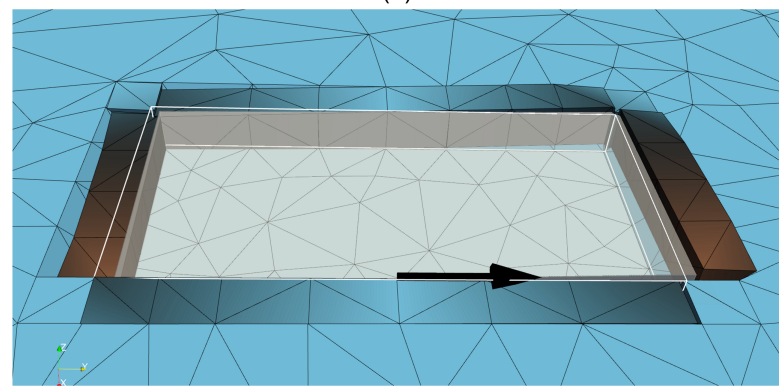

(d)

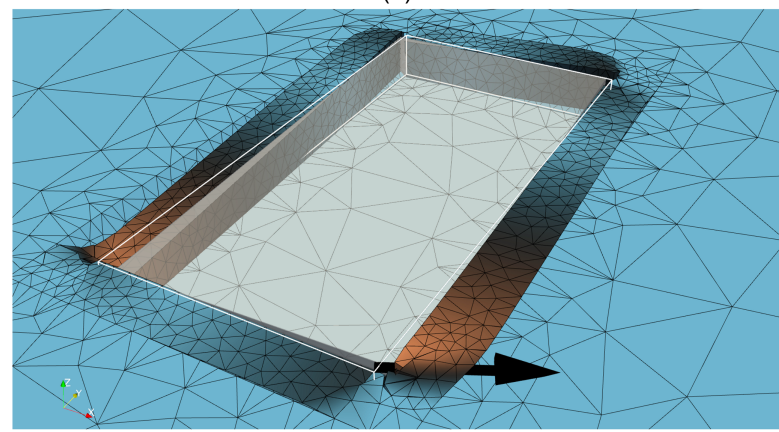

(f)

Figure 10: Failure mechanisms for an embedded footing $(d / B=0.2)$ subject to horizontal loading in various directions, applied concentrically and at the maximum feasible eccentricity: (a) $F_{x}, e / B=0$; (b) $F_{x}$, $e / B=1$; (c) $F_{y}, e / B=0$; (d) $F_{y}, e / B=0.5$; (e) $F_{\theta=26.6^{\circ}}, e / B=0$; (f) $F_{\theta=26.6^{\circ}}, e / B=1.12 . T=\infty$ on sides. Shaded by UB velocity magnitude

\subsection{Surface footing - horizontal, torsional and moment loading}

Figures 11(a), 11(e) and 11(i) show the capacity of a surface footing subject to horizontal forces applied at a range of eccentricities from, and heights above, the load reference point. When $e / B=0$ and $h / B=0$ the capacity of a surface footing is the same whether the footing is loaded by $F_{x}, F_{y}$ or $F_{\theta=26.6^{\circ}}$ (corresponding to the circular failure locus when $M_{z}$ $=0$ in Fig. 6(a)). When these forces are applied at a normalised height $h / B=0.5$, there is no reduction in capacity compared with $h / B=0$, and failure still occurs though interface shearing between the footing and the soil. When $F_{x}$ and $F_{\theta=26.6^{\circ}}$ are applied at a height $h / B=1$ there is a small reduction in capacity compared with the same forces applied at $h / B=0$, but no reduction for $F_{y}$. When $h / B=2$ the reduction in capacity is substantial for $F_{x}$ and $F_{\theta=26.6^{\circ}}$, but there is still only a minor reduction in capacity for a footing subject to $F_{y}$ at this height.

The reduction in capacity when the footing is subject to $F_{x}$ or $F_{\theta=26.6^{\circ}}$ at $h / B>0.5$ can be attributed to the increased overturning moment acting on the footing, and the effect can be seen in the failure mechanism. Figure 12 shows failure mechanisms for a footing subject to forces in various directions at a height $h / B=2 . F_{x}$ and $F_{\theta=26.6^{\circ}}$ cause failure by 'rolling' about the $y$-axis (Figs 12(a) and 12(c)), whereas $F_{y}$ predominantly causes failure through 

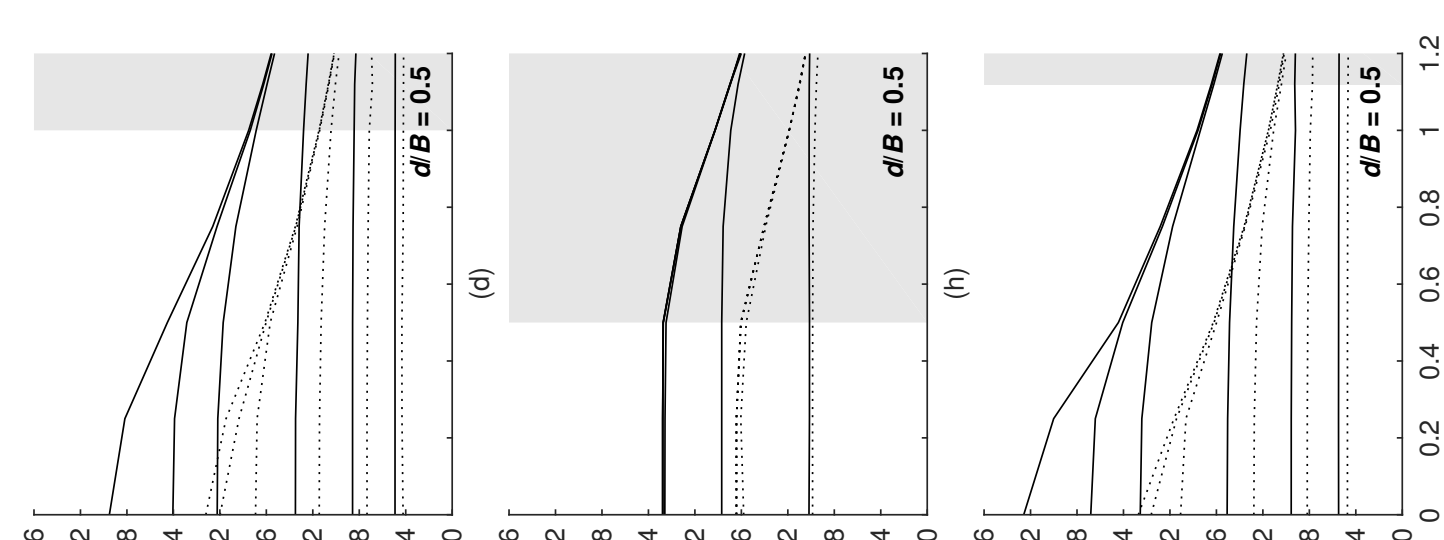

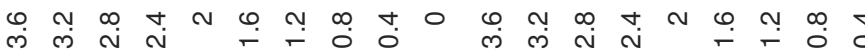
$\mathrm{n}^{278 I^{x}=1}$ $\mathrm{n} \mathrm{s} / \mathrm{K}$
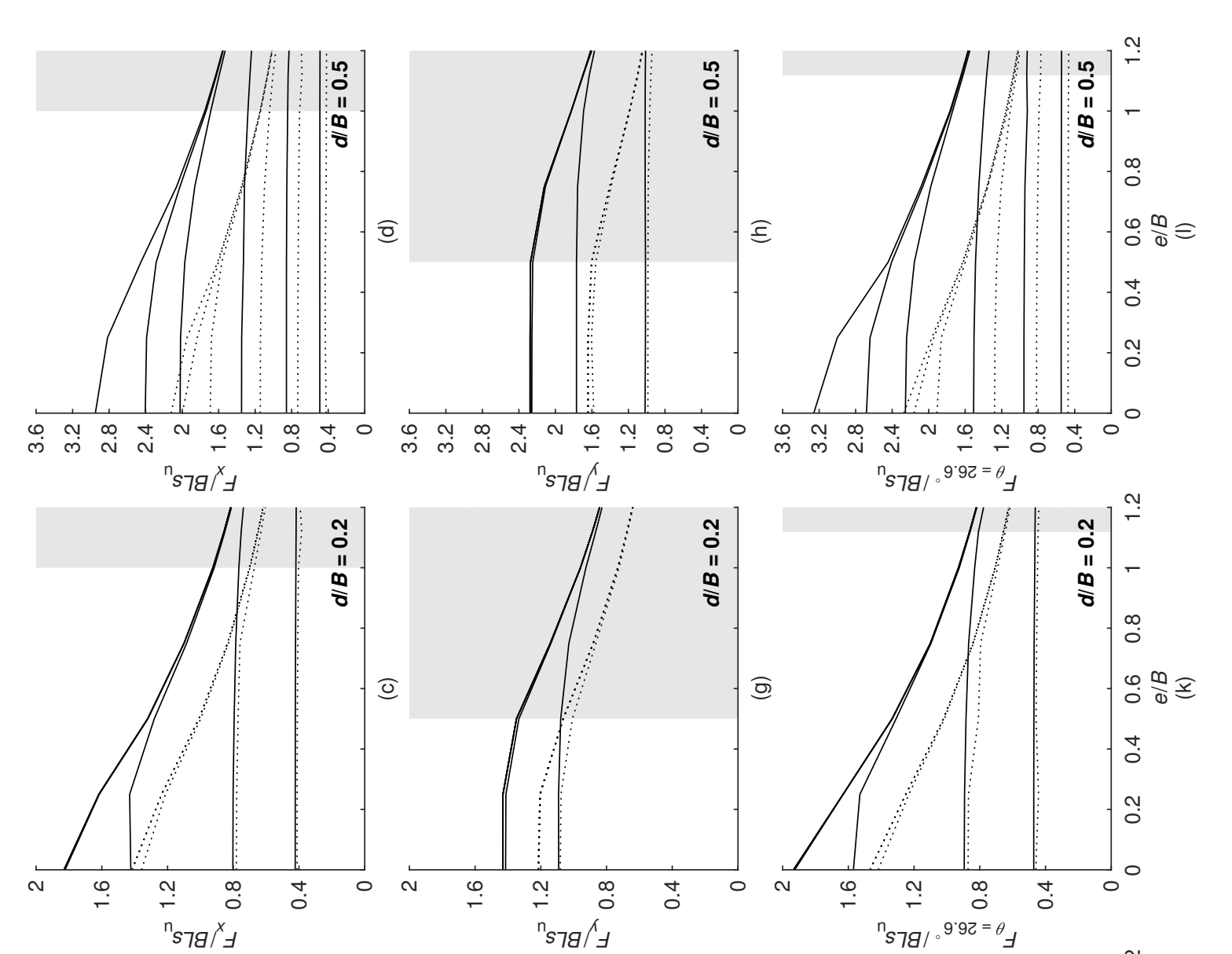

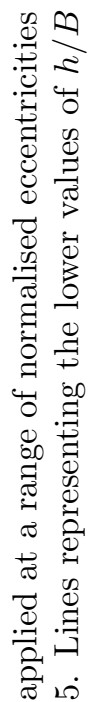

की

冚 $0 \quad 0$

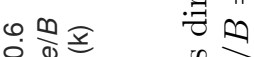

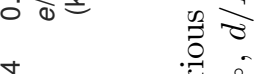
范 กับ 范 .7 II : 苛
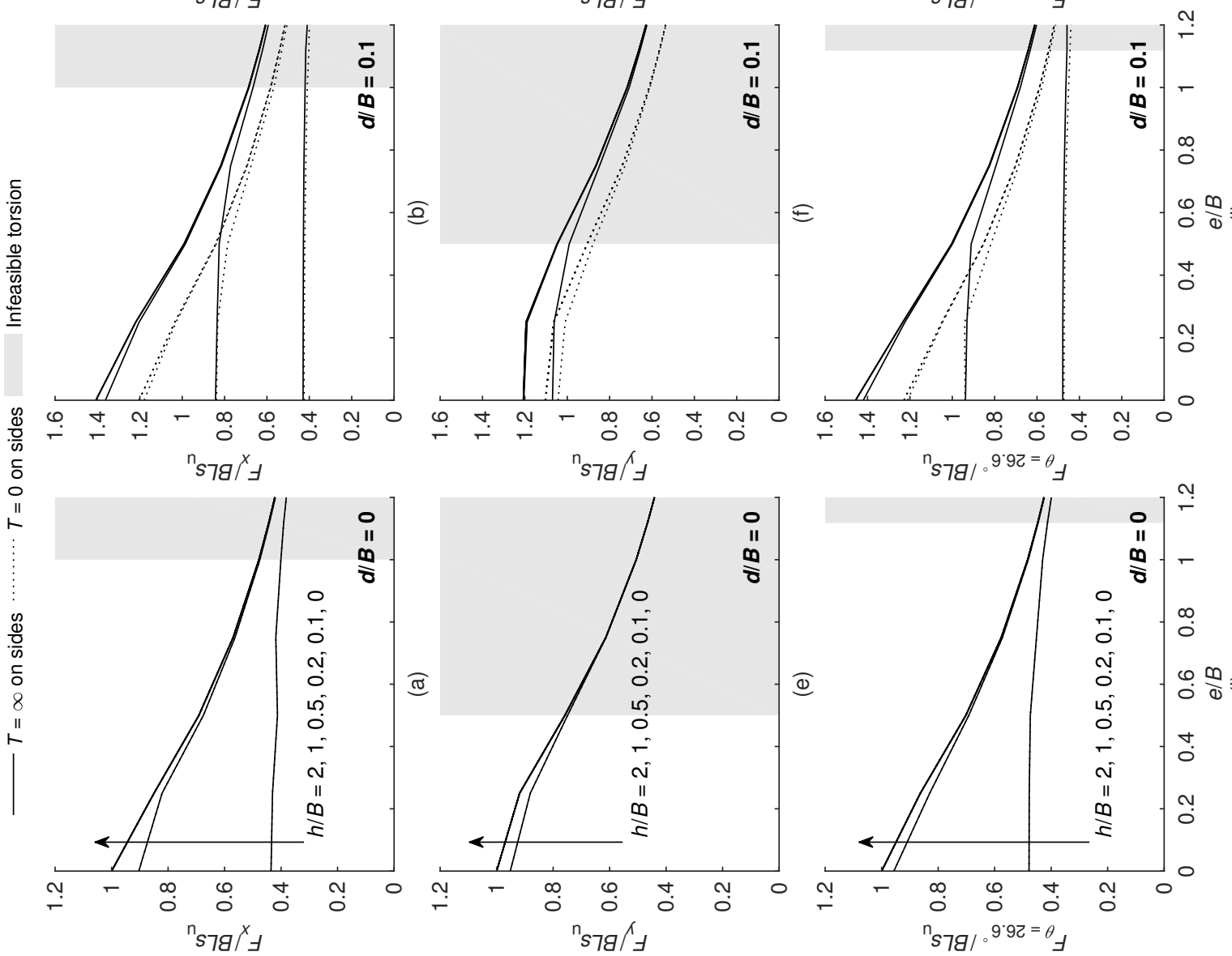

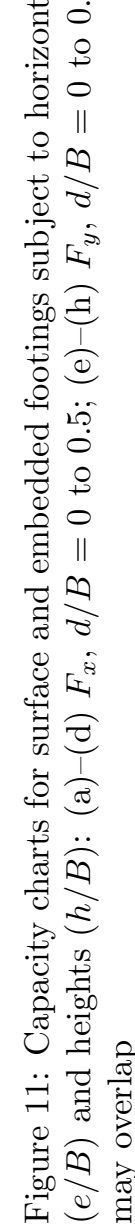


translation in the $y$-direction, with very little rotation (Fig. 12(b)). This is consistent with the increased moment capacity associated with 'pitching' rotation about the $x$-axis.

For a given height of load application, the capacity reduces as the normalised eccentricity $e / B$ increases due to the additional torsional moment acting on the footing. This reduction is less apparent when the footing is loaded at a height $h / B=2$ by $F_{x}$ or $F_{\theta=26.6^{\circ}}$, as failure is still dominated by rolling about the $y$-axis and not twisting about the $z$-axis. Failure mechanisms are presented in Fig. 13 for a surface footing subject to loading by $F_{\theta=26.6^{\circ}}$. When $F_{\theta=26.6^{\circ}}$ is applied at $h / B=0$ and $e / B=0$, failure occurs through translation with no rotation or twist (Fig. 13(a)). When $F_{\theta=26.6^{\circ}}$ is applied with increasing eccentricity, the footing fails through translation as well as increasing amounts of twist (Figs 13(b) and 13(c)). This corresponds to the steep reduction in capacity when $h / B=0$ and $0 \leq e / B \leq 1.12$ in Fig. 11(i). A footing subject to $F_{\theta=26.6^{\circ}}$ at $h / B=2$ and $e / B=0$ fails through rotation about the $y$-axis (Fig. 13(d)). The failure mechanism does not change significantly as $e / B$ increases to 0.5 (Fig. 13(e)), which corresponds to no change in capacity when $h / B=2$ and $0 \leq e / B \leq 0.5$ in Fig. 11(i). When $e / B=1.12$, twisting is visible in the failure mechanism (Fig. 13(f)), and the capacity reduces slightly (Fig. 11(i)).

\subsection{Embedded footing - horizontal, torsional and moment loading}

When a footing is loaded by $F_{x}$ or $F_{\theta=26.6^{\circ}}$, footing embedment does not significantly influence the rate of reduction in capacity as the eccentricity of the horizontal load increases (Fig. 11). For example, a surface footing subject to $F_{\theta=26.6^{\circ}}$ undergoes a $55 \%$ reduction in capacity as $e / B$ increases from 0 to 1.12 (Fig. 11(i)) and a footing embedded with $d / B=0.5$ undergoes a $53 \%$ reduction in capacity (Fig. 11(l)). However, an embedded footing subject to $F_{y}$ loading shows better performance under torsional loading. In this instance, a surface footing subject to $F_{y}$ undergoes a $26 \%$ reduction in capacity as $e / B$ increases from 0 to 0.5 (Fig. 11(e)), but if the footing is embedded with $d / B=0.5$, the capacity does not change over the same range of $e / B$ (Fig. 11(h)).

As with a surface footing, when an embedded footing is subject to a horizontal force applied at a height $h$, there is generally no reduction in capacity until a critical height is reached, whereupon the capacity reduces rapidly. However, the critical height reduces with increasing mudmat embedment. This can be attributed to the increased lever arm from the load to the base of the mudmat. Figure 14 shows failure mechanisms for footings with various embedment ratios, subject to $F_{y}$ loading applied at $h / B=1$. A surface footing fails through interface shearing between the footing and the soil, and the footing translates horizontally (Fig. 14(a)). A footing embedded with $d / B=0.2$ also translates horizontally at failure, but displaces wedges of soil (Fig. 14(b)). However, the failure mechanism for a footing embedded with $d / B=0.5$ changes to pitching about the $x$-axis (Fig. 14(c)).

When the total lever arm from the load to the base of the mudmat is considered, a surface footing subject to $F_{x}$ loading has a similar capacity to a footing embedded with $d / B$ $=0.5$. The capacity of a surface footing loaded by $F_{x}$ at $h / B=1$ is $0.9 B L s_{\mathrm{u}}$ (Fig. 11(a)), while a footing embedded with $d / B=0.5$ loaded by $F_{x}$ at $h / B=0.5$, such that the effective lever arm $(h+d) / B=1$, has a capacity of $0.86 B L s_{\mathrm{u}}$ (Fig. 11(d)).

\subsection{Horizontal, torsional, moment and vertical loading}

The ultimate vertical bearing capacities $F_{z 0}$ of surface and embedded footings (assuming unlimited tension capacity on the sides) were closely bracketed using FELA, and results are presented in Table 1. For selected embedment ratios $d / B$, a vertical dead load of magnitude $0.5 F_{z 0}$ was applied to the footing while it was again subjected to live horizontal loads applied 


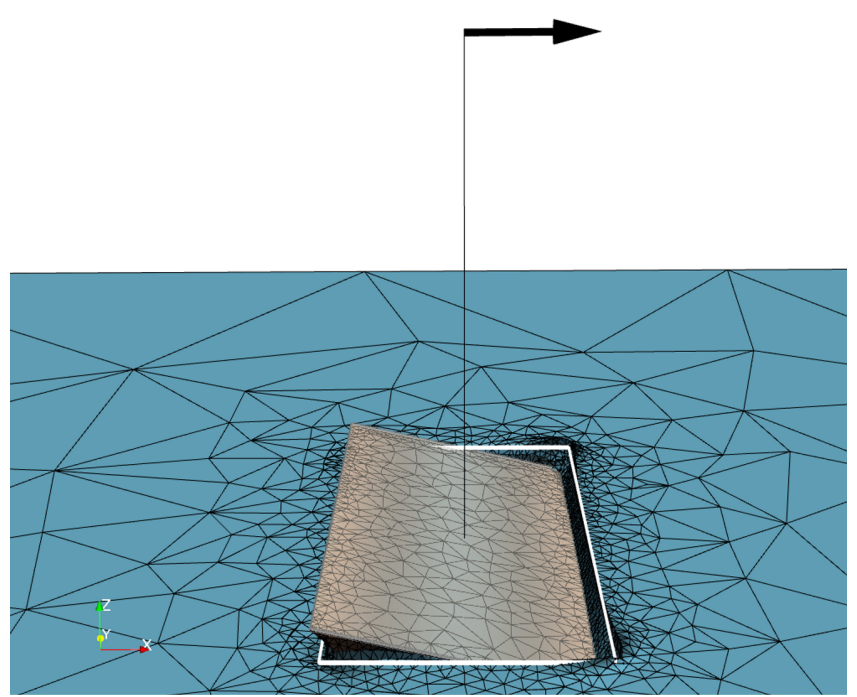

(a)

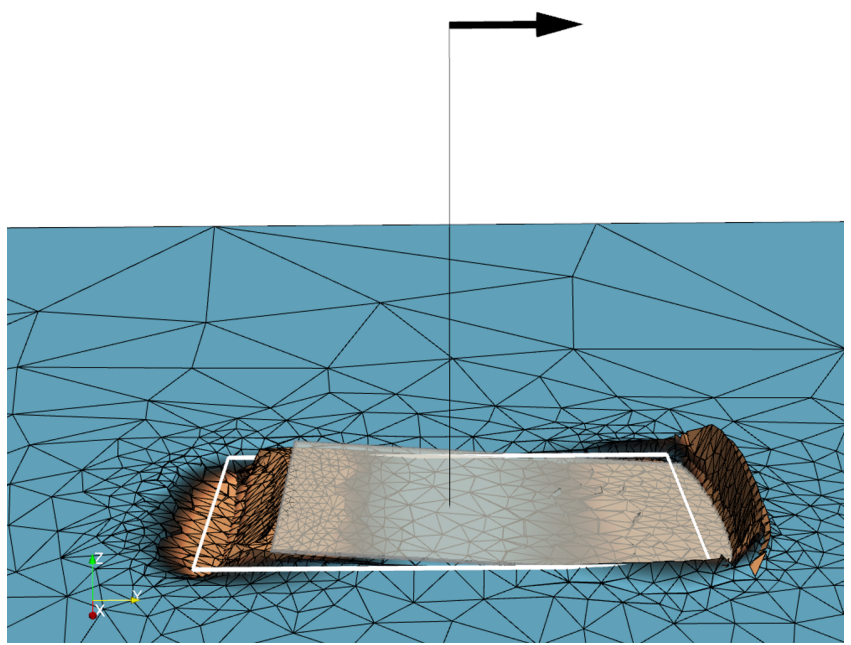

(b)

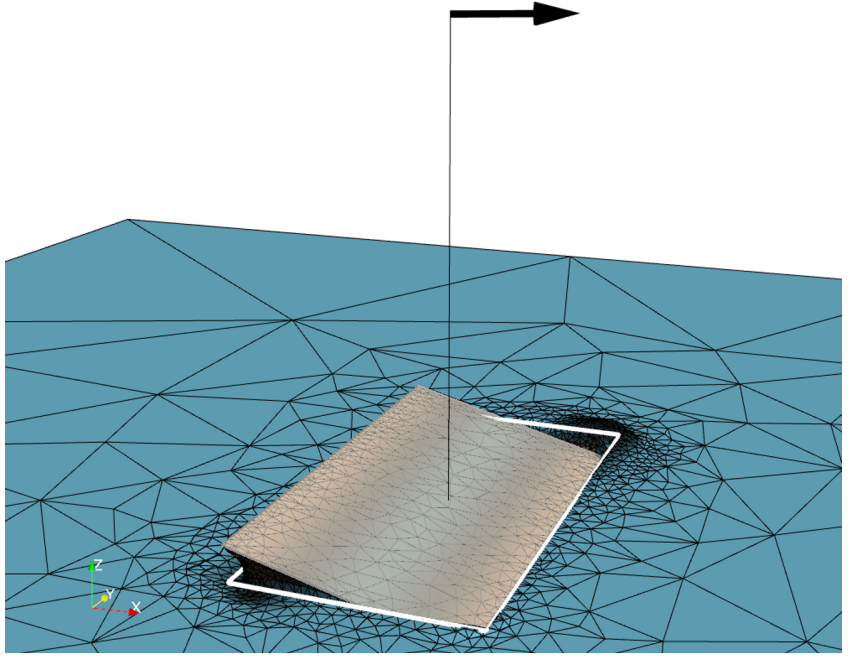

(c)

Figure 12: Failure mechanisms for a surface footing subject to horizontal loading in various directions,

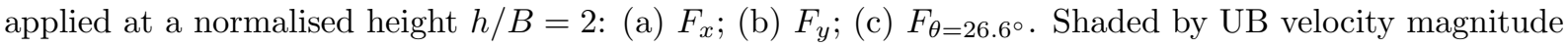




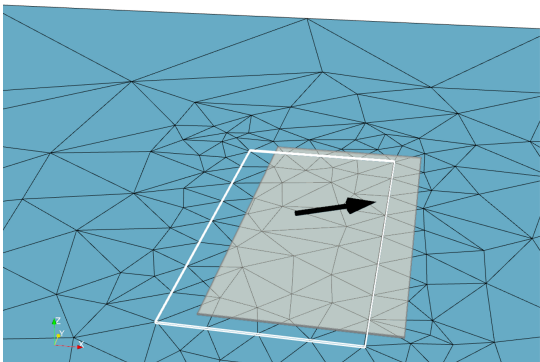

(a)

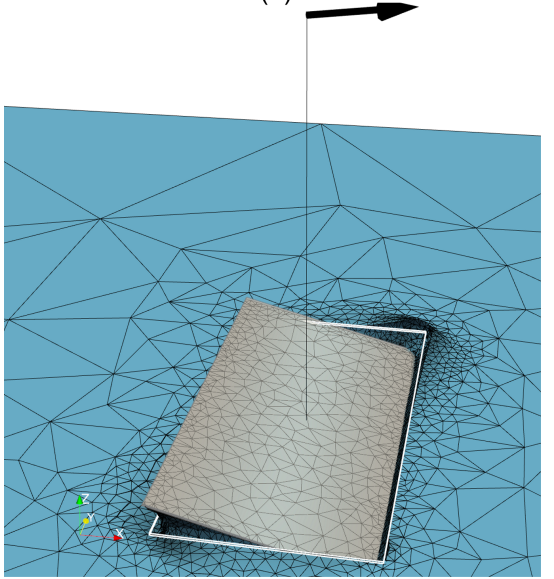

(d)

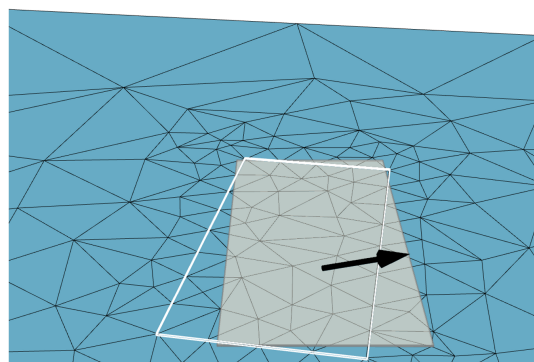

(b)

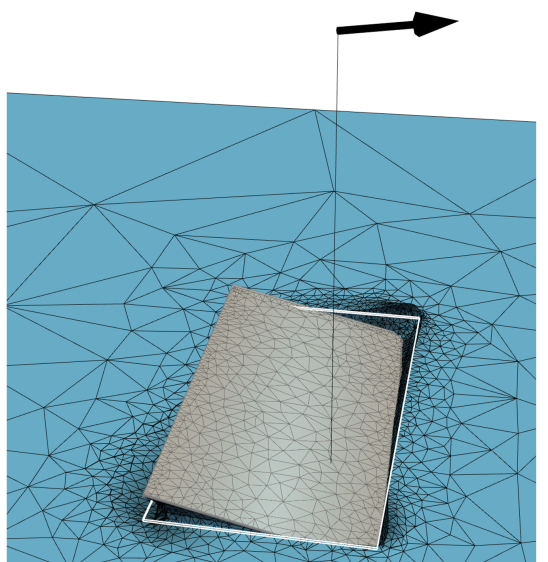

(e)

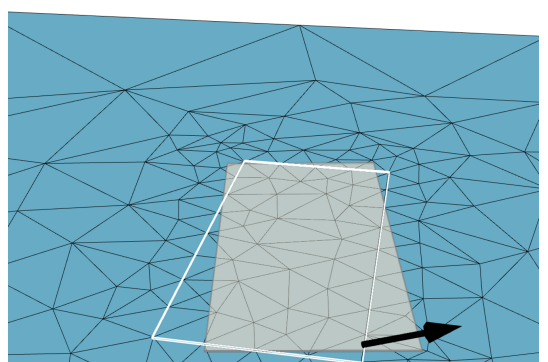

(c)

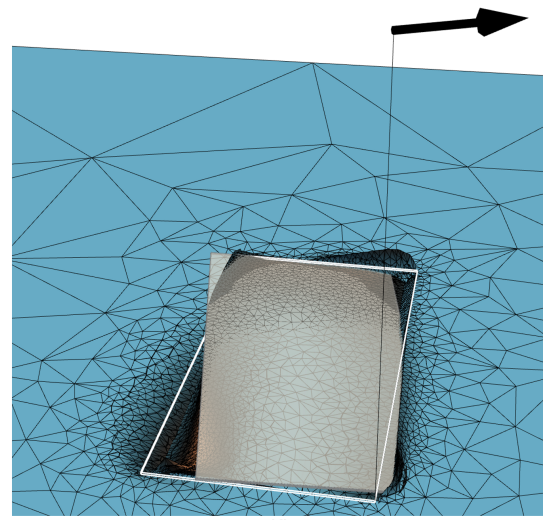

(f)

Figure 13: Failure mechanisms for a surface footing subject to horizontal loading $F_{\theta=26.6^{\circ}}$, showing effect of eccentricity and height of application: (a) $e / B=0, h / B=0 ;$ (b) $e / B=0.5, h / B=0 ;(\mathrm{c}) e / B=1.12$, $h / B=0 ;(\mathrm{d}) e / B=0, h / B=2 ;$ (e) $e / B=0.5, h / B=2 ;$ (f) $e / B=1.12, h / B=2$.. Shaded by UB velocity magnitude

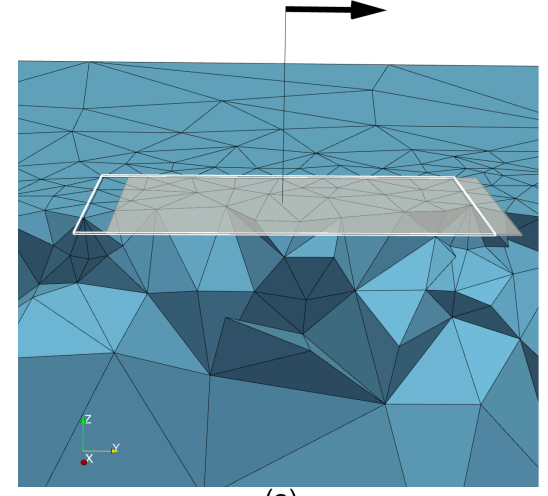

(a)

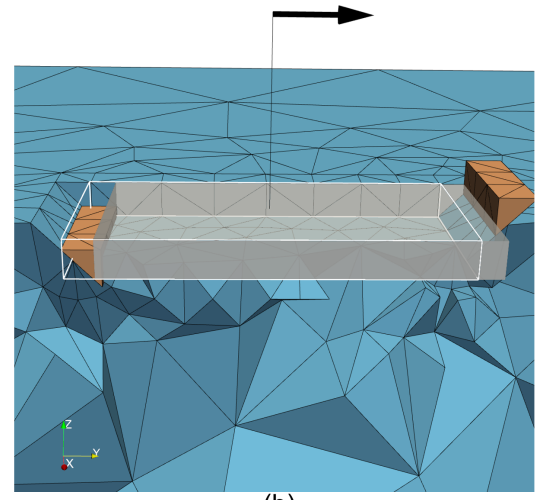

(b)

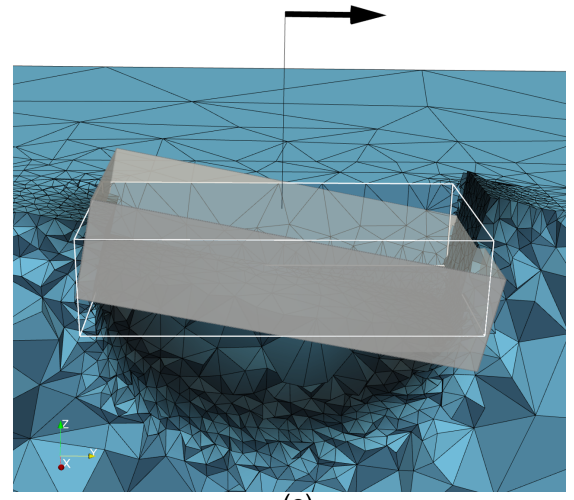

(c)

Figure 14: Failure mechanisms for footings subject to horizontal loading $F_{y}$ applied at a normalised height $h / B=1$, showing effect of embedment: (a) $d / B=0 ;$ (b) $d / B=0.2 ;$ (c) $d / B=0.5$. $T=\infty$ on sides. Shaded by UB velocity magnitude

at various eccentricities from, and heights above, the load reference point. Capacities for footings with and without a vertical dead load are presented in Fig. 15 for the two extreme cases of embedment considered here $(d / B=0,0.5)$. It is apparent that the addition of a substantial vertical dead load (much higher than would be typical for a mudmat in the field) has no significant effect on the capacity under horizontal loading in conjunction with feasible levels of torsional and moment loading. Note that because the base and sides of the mudmat have been assumed to have unlimited tension capacity, the results in Fig. 15 are 


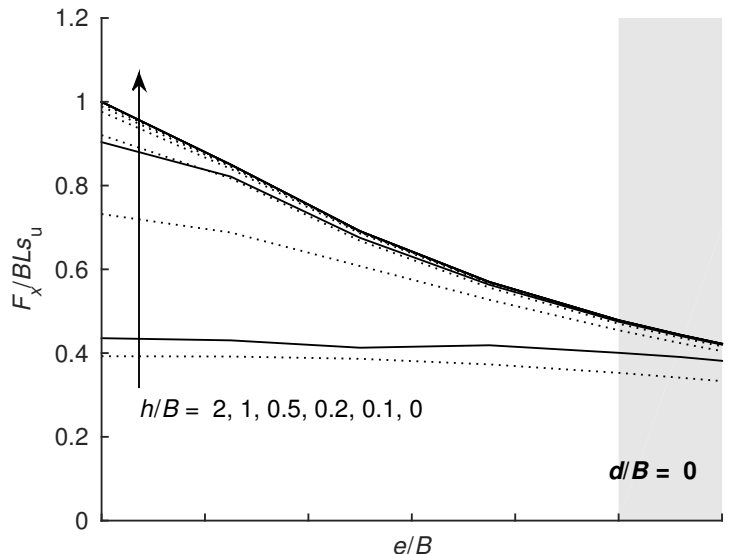

(a)

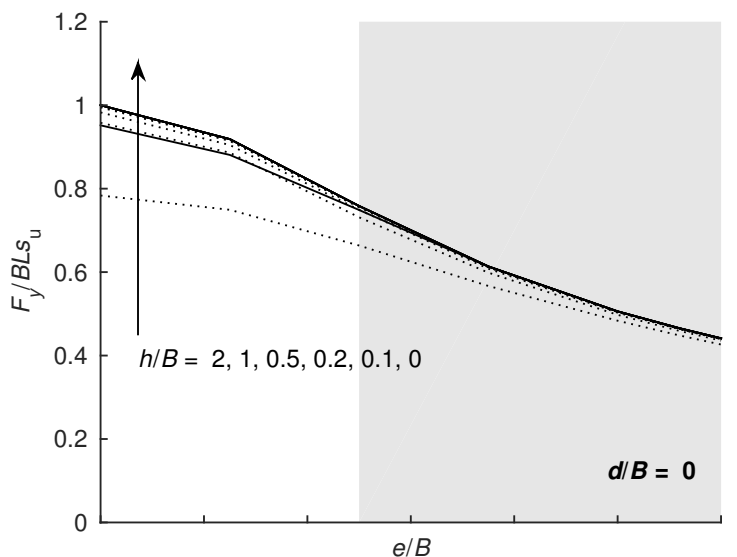

(c)

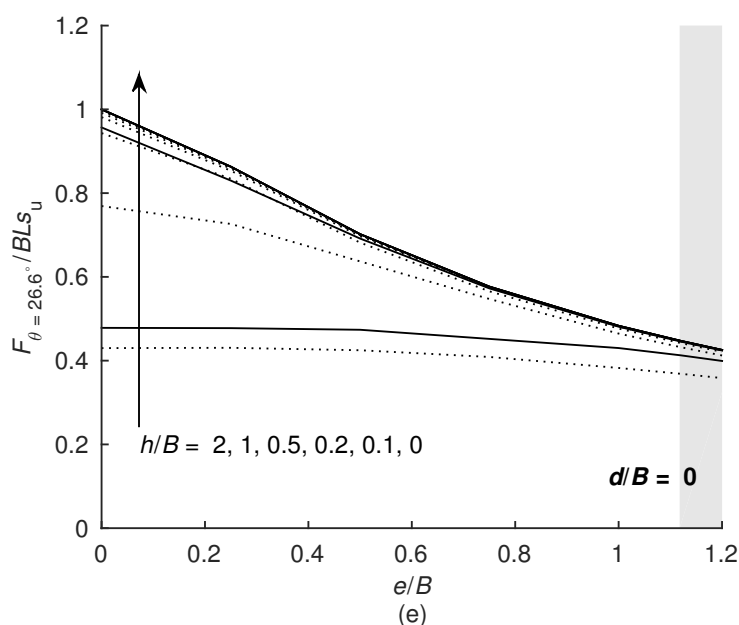

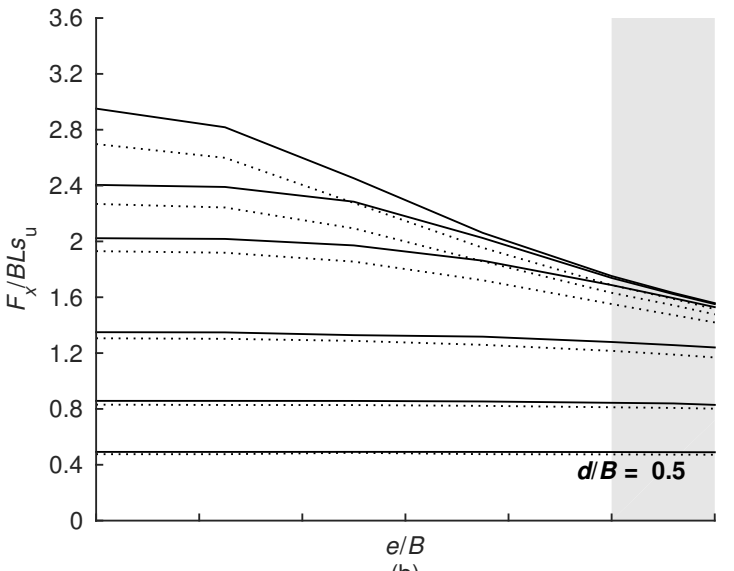

(b)

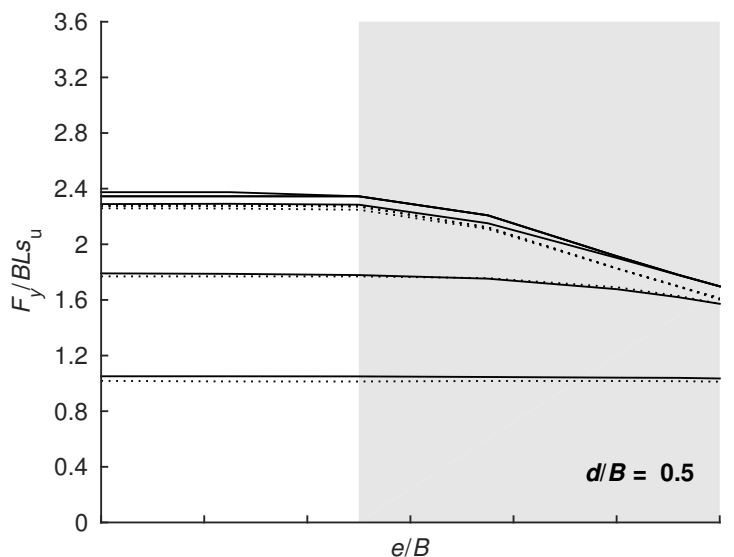

(d)

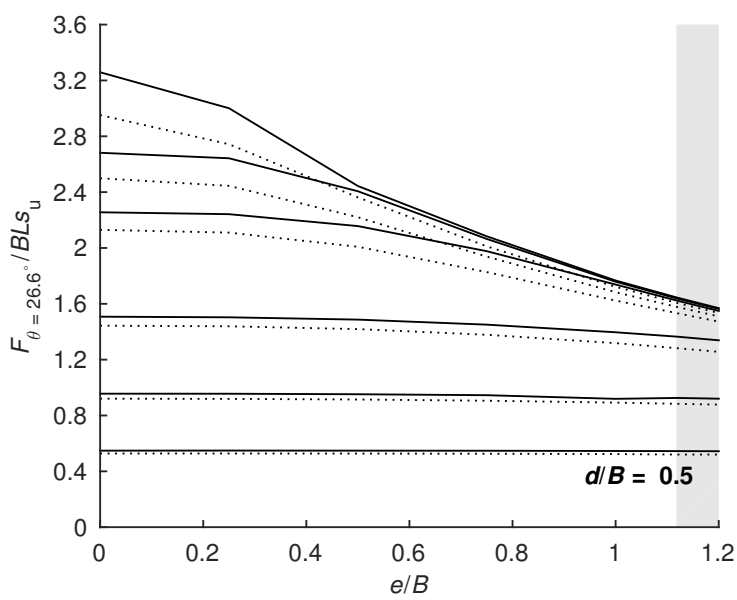

(f)

Figure 15: Capacity charts for surface and embedded footings subject to horizontal loading in various directions, applied at a range of normalised eccentricities $(e / B)$ and heights $(h / B)$, in conjunction with a vertical dead load $F_{z}=0$ or $F_{z}=0.5 F_{z 0}$ : (a) $F_{x}, d / B=0 ;$ (b) $F_{x}, d / B=0.5 ;$ (c) $F_{y}, d / B=0 ;$ (d) $F_{y}$, $d / B=0.5$; (e) $F_{\theta=26.6^{\circ}}, d / B=0$; (f) $F_{\theta=26.6^{\circ}}, d / B=0$. Lines representing the lower values of $h / B$ may overlap 
Table 1: Normalised vertical bearing capacities $\left(F_{z 0} / B L s_{\mathrm{u}}\right)$ for surface and embedded footings obtained using FELA. $T=\infty$ on sides

\begin{tabular}{lllll}
\hline Embedment ratio, $d / B$ & 0 & 0.1 & 0.2 & 0.5 \\
LB & 5.33 & 5.77 & 6.13 & 6.78 \\
UB & 5.73 & 6.34 & 6.70 & 7.38 \\
Average & 5.53 & 6.06 & 6.42 & 7.08 \\
Bracketing error: \% & \pm 3.6 & \pm 4.7 & \pm 4.5 & \pm 4.3 \\
\hline
\end{tabular}

unaffected by the direction of the vertical dead load (upward or downward).

\section{Conclusions}

This study has focused on the ultimate limit state analysis of offshore mudmats on soft clays, where undrained capacity is critical for design. A range of effects were explored, including the embedment of the mudmat, the interface tension capacity on the sides of the mudmat, and soil weight. Rigorous 3D limit load analyses were carried out using both analytical calculations and FELA. Horizontal forces were applied to the mudmat at a range of eccentricities from, and heights above, its load reference point (encompassing five degreeof-freedom loading). Particular attention was given to identifying the levels of torsion and overturning moment that may realistically arise from horizontal loading applied within the envelope of the mudmat and the equipment that it supports. In the final stage of the study, the effect of a concurrent vertical dead load was considered.

Applying a horizontal load at an eccentricity from the footing centre generates a torsional load component. The results quantify the gradual reduction in capacity as the eccentricity of a horizontal force increases. Depending on the degree of embedment, the failure mechanism in this case can change from pure translation to combined translation and twisting. Mudmat embedment helps to negate the reduction in capacity due to eccentric loading, particularly when the load is aligned with the longer side of the footing.

A horizontal load applied at a height above the footing causes no reduction in capacity until a critical height is reached, whereupon the capacity reduces rapidly (see Fig. 11). This threshold was found to be higher when the horizontal force is aligned parallel to the longer side of the footing. The failure mechanism changes from pure translation to combined translation and rotation once the threshold has been reached. Mudmat embedment causes a reduction in the threshold height, since the effective lever arm from the load to the mudmat base is larger.

A vertical dead load equal to (or less than) half of the ultimate vertical capacity can be applied to a mudmat without any significant effect on the resistance to horizontal loading in conjunction with practically feasible levels of torsional and moment loading.

3D FELA with adaptive mesh refinement was found to be an effective method for analysing the bearing capacity of rectangular shallow foundations embedded in undrained clay subject to complex 3D loading. FELA results for a surface footing subject to combined horizontal and torsional loading showed excellent agreement with results from an analytical solution that gave coincident lower and upper bounds. Combining LB and UB FELA proved beneficial as the bracketing error was often sufficiently small after the first iteration of the analysis that adaptive mesh refinement was not necessary. 
This research could usefully be extended to soil with increasing undrained shear strength with depth. A comparison of the von Mises and Tresca failure criteria for footings under combined six degree-of-freedom loading would also be of interest.

\section{Acknowledgements}

The first author is grateful for financial support received from Subsea 7.

\section{References}

Bransby, M.F. \& Randolph, M.F. (1998). Combined loading of skirted foundations. Géotechnique 48, No. 5, 637-655.

Brinch Hansen, J. (1970). A revised and extended formula for bearing capacity. Bulletin No. 28, Danish Geotechnical Institute, Copenhagen, 5-11.

Dimmock, P., Clukey, E., Randolph, M.F., Murff, D. \& Gaudin, C. (2013). Hybrid subsea foundations for subsea equipment. J. Geotech. Geoenviron. Engng 139, No. 12, 2182-2192.

DNV (1992). Classification Notes No. 30.4, Foundations. Det Norske Veritas, Oslo, Norway.

Dunne, H.P., Martin, C.M., Muir, L., Brown, N. \& Wallerand, R. (2015). Undrained bearing capacity of skirted mudmats on inclined seabeds. Proc. 3rd Int. Symp. on Frontiers in Offshore Geotech., Oslo 2, 783-788.

Feng, X., Randolph, M.F., Gourvenec, S. \& Wallerand, R. (2014). Design approach for rectangular mudmats under fully three-dimensional loading. Géotechnique 64, No. 1, 51-63.

Finnie, I.M.S. \& Morgan, N. (2004). Torsional loading of subsea structures. Proc. 14th Int. Offshore and Polar Engineering Conf., Toulon, 326-333.

Gourvenec, S., Randolph, M.F. \& Kingsnorth, O. (2006). Undrained bearing capacity of square and rectangular footings. Int. J. Geomech. 6, No. 3, 147-157.

ISO (2003). ISO 19901-4: Petroleum and Natural Gas Industries - Specific Requirements for Offshore Structures - Part 4: Geotechnical and Foundation Design Considerations, 1st edn. International Organisation for Standardisation, Geneva, Switzerland.

Mana, D.S.K., Gourvenec, S. \& Martin, C.M. (2013). Critical skirt spacing for shallow foundations under general loading. J. Geotech. Geoenviron. Engng 139, No. 9, 1554-1566.

Makrodimopoulos, A. \& Martin, C.M. (2006). Lower bound limit analysis of cohesivefrictional materials using second-order cone programming. Int. J. Num. Meth. Engng 66, No. 4, 604-634.

Makrodimopoulos, A. \& Martin, C.M. (2007). Upper bound limit analysis using simplex strain elements and second-order cone programming. Int. J. Num. Anal. Meth. Geomech. 
31, No. 6, 835-865.

Martin, C.M. (1994). Physical and numerical modelling of offshore foundations under combined loads. DPhil thesis, University of Oxford.

Martin, C.M. (2011). The use of adaptive finite-element limit analysis to reveal slip-line fields. Géotechnique Letters 1, No. 2, 23-29.

Martin, C.M. \& Makrodimopoulos, A. (2008). Finite-element limit analysis of MohrCoulomb materials in 3D using semidefinite programming. J. Eng. Mech. 134, No. 4, 339-347.

Martin, C.M. \& White, D.J. (2012). Limit analysis of the undrained bearing capacity of offshore pipelines. Géotechnique 62, No. 9, 847-863.

Martin, C.M., Dunne, H.P., Wallerand, R. \& Brown, N. (2015). Three-dimensional limit analysis of rectangular mudmat foundations. Proc. 3rd Int. Symp. on Frontiers in Offshore Geotech., Oslo 2, 789-794.

McDonald, S., Suroor, H., Malachowski, J., Wang, Q. \& Qi, X. (2014). Analysis of subsea foundations subjected to significant torsion. Proc. 33rd Int. Conf. on Ocean, Offshore and Arctic Engng, San Francisco, Paper No. OMAE2014-24192.

MOSEK ApS (2014). The MOSEK C Optimizer API manual, Version 7.1. See http://www.mosek.com . Accessed 10/02/2016.

Murff, J.D., Aubeny, C.P. \& Yang, M. (2010). The effect of torsion on the sliding resistance of rectangular foundations. Proc. 2nd Int. Symp. on Frontiers in Offshore Geotech., Perth, $439-444$.

Murff, J.D. \& Miller, T.W. (1977). Stability of offshore gravity structure foundations by the upper bound method. Proc. Offshore Technology Conference, Houston, Paper No. OTC 2896.

Nouri, H., Biscontin, G. \& Aubeny, C.P. (2014). Undrained sliding resistance of shallow foundations subject to torsion. J. Geotech. Geoenviron. Engng 140, No. 8.

Si, H. 2013. TetGen User's Manual, Version 1.5.

See http://wias-berlin.de/software/tetgen/1.5/doc/manual/index.html.

Accessed 10/02/2016.

Ukritchon, B., Whittle, A. J. \& Sloan, S. W. (1998). Undrained limit analysis for combined loading of strip footings on clay. J. Geotech. Geoenviron. Engng 124, No. 3, 265-276.

Vesic, A.S. (1975). Bearing capacity of shallow foundations. In Foundation Engineering Handbook (eds H. F. Winterkorn and H. Y. Fang), 121-147. New York: Van Nostrand.

Yun, G.J., Maconochie, A., Oliphant J., \& Bransby, M.F. (2009). Undrained capacity of 
surface footings subjected to combined $V-H-T$ loading. Proc. 19th Int. Offshore and Polar Eng. Conf., Osaka 2, 9-14. 